Article

\title{
Evaluation of The Seismic Hazard in The Marmara Region (Turkey) Based on Updated Databases
}

\author{
Karin Şeşetyan ${ }^{1, *}$, Mine Betül Demircioğlu Tümsa ${ }^{2}$ and Aybige Akinci ${ }^{3}$ \\ 1 Department of Earthquake Engineering, Kandilli Observatory and Earthquake Research Institute, \\ Boğaziçi University, Cengelkoy, 34684 Istanbul, Turkey \\ 2 MD Consulting Engineers, Caferağa Mah., Keresteci Aziz Sk. No:5/33, Kadikoy, 34710 Istanbul, Turkey; \\ minebd@gmail.com \\ 3 Istituto Nazionale di Geofisica e Vulcanalogia, Via di Vigna Murata 605, 00143 Rome, Italy; \\ aybige.akinci@ingv.it \\ * Correspondence: karin@boun.edu.tr; Tel.: +90-21-6516-3229
}

Received: 7 October 2019; Accepted: 10 November 2019; Published: 20 November 2019

\begin{abstract}
The increase in the wealth of information on the seismotectonic structure of the Marmara region after two devastating earthquakes (M7.6 Izmit and M7.2 Duzce events) in the year 1999 opened the way for the reassessment of the probabilistic seismic hazard in the light of new datasets. In this connection, the most recent findings and outputs of different national and international projects concerning seismicity and fault characterization in terms of geometric and kinematic properties are exploited in the present study to build an updated seismic hazard model. A revised fault segmentation model, alternative earthquake rupture models under a Poisson and renewal assumptions, as well as recently derived global and regional ground motion prediction equations (GMPEs) are put together in the present model to assess the seismic hazard in the region. Probabilistic seismic hazard assessment (PSHA) is conducted based on characteristic earthquake modelling for the fault segments capable of producing large earthquakes and smoothed seismicity modelling for the background smaller magnitude earthquake activity. The time-independent and time-dependent seismic hazard results in terms of spatial distributions of three ground-shaking intensity measures (peak ground acceleration, PGA, and $0.2 \mathrm{~s}$ and $1.0 \mathrm{~s}$ spectral accelerations (SA) on rock having $10 \%$ and $2 \%$ probabilities of exceedance in 50 years) as well as the corresponding hazard curves for selected cities are shown and compared with previous studies.
\end{abstract}

Keywords: probabilistic seismic hazard assessment; renewal and Poisson models; Marmara Region; Turkey; North Anatolian Fault Zone

\section{Introduction}

The two destructive earthquakes that occurred in the Eastern part of Marmara region at the closing of the 20th century, namely the August 17, 1999, M7.6 Izmit and November 12, 1999, M7.2 Düzce earthquakes, have been a turning point in the community perception of the high seismic risk prevailing in Marmara region, which hosts several highly populated cities, among them Istanbul with its 15 million population and contributing to more than 30\% of Turkish GDP. Since the 1999 earthquakes, the mitigation of the seismic risk in the Marmara region and particularly in Istanbul has been a major aim and to this end several geological and seismological studies have been conducted for the characterization of seismic sources, especially within the Marmara Sea and for the identification of the associated earthquake potential that would enhance reliable estimations of the seismic hazard levels in the region. As such, as new data and methods emerge, updates of seismic hazard models also become indispensable. In fact, many recent studies indicate the high probability of having an 
earthquake with magnitude up to 7.4 especially on the fault segments in the Marmara Sea, passing from about $20 \mathrm{~km}$ south of the city of Istanbul [1-7]. Using time-dependent methods, the occurrence probability of large earthquakes $(M>7.0)$ in the Marmara Sea was calculated to be around $40 \%$ for the next 30 years starting from the year 2004 by [2] and the year 2016 by [3].

Following the 1999 earthquakes, in addition to the several research efforts on source characterization in Marmara region, a number of studies were conducted for the estimation of future ground motions in the region. Probabilistic seismic hazard models were developed by [8-11] using different earthquake rupture models and forecasts together with various ground motion prediction equations (GMPEs), while [12-15] used physics-based simulations to estimate ground motion distributions from future fault ruptures. Spagnuolo et al. [16] analysed the effects of the rupture directivity on the seismic hazard in Marmara region.

The common point of the recent probabilistic seismic hazard assessment studies was that they have addressed the seismic hazard based on fault source modelling with characteristic recurrence through the commonly used Poissonian and/or more complicated renewal models (e.g., $[17,18]$ for Italy, [9-11] for Marmara). For the Marmara region, this preference was driven by several aspects such as (1) the region has experienced a large number of $\mathbf{M}>7$ earthquakes with some regional periodicity over the last thousand years; (2) the area to the west of the 1999 Izmit earthquake which is also affected by the post-earthquake positive stress transfer is a candidate to produce large earthquakes, with almost $150 \mathrm{~km}$ long un-ruptured segments representing a seismic gap in the Marmara sea; 3 ) following the 1999 Izmit and Düzce earthquakes, many important projects and studies made significant contributions to the knowledge on both on- and off-shore seismic sources to set up a complete regional fault model to be used for the seismic hazard studies.

The present study aimed at a reassessment of the probabilistic seismic hazard in the Marmara region using recent findings and outputs of different national and international projects in terms of seismicity, fault geometry and slip rates. An updated fault segmentation model and several earthquake recurrence estimations together with recently derived global and regional ground motion prediction equations (GMPEs) are utilized to assess the seismic hazard in the area. We first introduce the earthquake catalogue and finite fault sources with their corresponding statistical, geometrical and kinematical aspects; then probabilistic seismic hazard assessment (PSHA) methods based on seismicity (smoothed seismicity approach) or individual fault ruptures (characteristic earthquake model) are implemented and the effect of the different earthquake occurrence models on the hazard estimations is investigated. The epistemic uncertainties in ground motion estimations for given earthquake magnitude and distance couples are treated via a logic tree at the GMPE level of the hazard model.

Regarding the seismic hazard computations, we have used the freely available Openquake software [19]. Final results are given in terms of peak ground acceleration (PGA) and $0.2 \mathrm{~s}$ and $1.0 \mathrm{~s}$ spectral acceleration (SA) distributions for engineering bedrock (upper 30m shear wave velocity, Vs30, of $760 \mathrm{~m} / \mathrm{s}$ ) having $10 \%$ and $2 \%$ probabilities of exceedance in 50 years (corresponding to return periods of 475 years and 2475 years respectively) as well as hazard curves corresponding to the same ground motion parameters for selected cities. The ground motion estimations are compared with those from earlier studies and differences are discussed. A general map of the study region is provided in Figure 1, where we present the fault ruptures associated with large earthquakes that occurred in the 20th century, as well as the locations of the four cities mentioned above. 


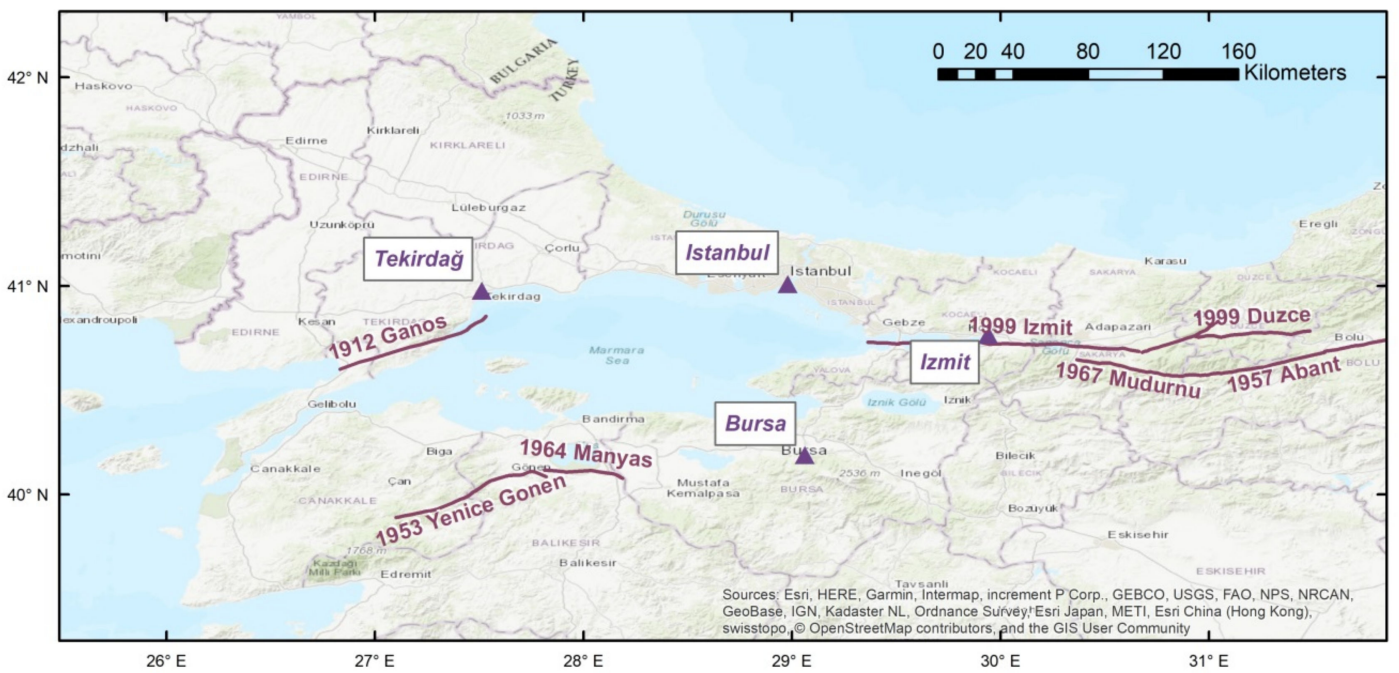

Figure 1. A general map of the study region. The linear features represent the earthquake ruptures of the 20th century. The triangles indicate the locations of the four cities for which we provide hazard curves.

\section{Review of Previous Efforts}

Regional probabilistic seismic hazard assessment models for the Marmara region were developed after the 1999 Izmit and Düzce earthquakes. Earlier assessments were conducted for Turkey in general (e.g., [20]), in which seismic sources in the Marmara region were represented by mainly two large areal sources, standing for the northern and southern branches of the North Anatolian Fault in the Marmara Sea. At the source modelling level, region-specific studies which were later developed relied more on fault segmentation and associated parameters. Atakan et al. [8] conducted a seismic hazard study with three different source models, one with broad areal sources similar to the ones extracted from [20] for Turkey, the second and third ones with narrow areal sources representing the fault segments in the Marmara region (Figure 2a,b). Characteristic magnitude recurrence and time-dependent hazard computation methods were adopted for the second and third models. Erdik et al. [9] used both Poissonian and time-dependent methods in association with a fault source model developed for the Marmara region (Figure 2c) with characteristic recurrence, combined with smoothed background seismicity. Kalkan et al. [10] proposed an alternative model again based on fault sources (Figure 2d) and smoothed seismicity, earthquake recurrence on faults being represented by both exponential and characteristic models, the results of which combined in a logic tree. Gülerce and Ocak [11] proposed a seismic hazard model for the eastern part of the Marmara region, between longitudes $29-31.5^{\circ} \mathrm{E}$ and latitudes $40.3-40.9^{\circ} \mathrm{N}$ (Figure 3). The composite recurrence model of [21] was adopted and segments were allowed to break individually or to accommodate cascading ruptures.

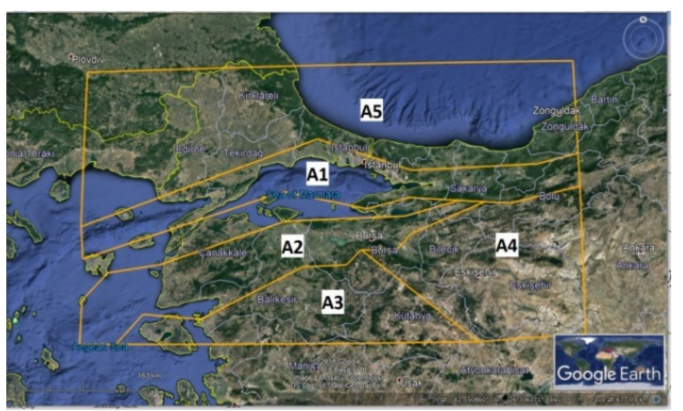

(a)

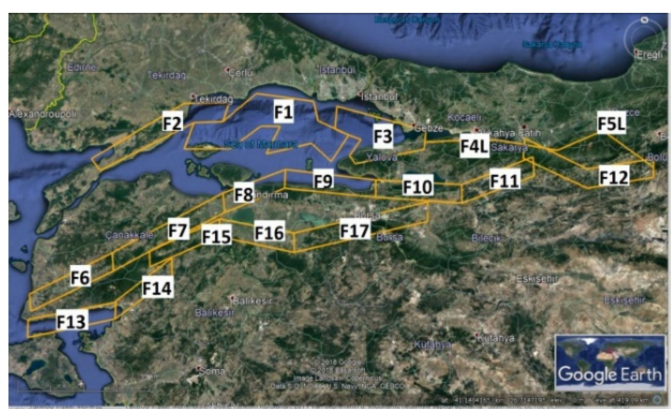

(b)

Figure 2. Cont. 


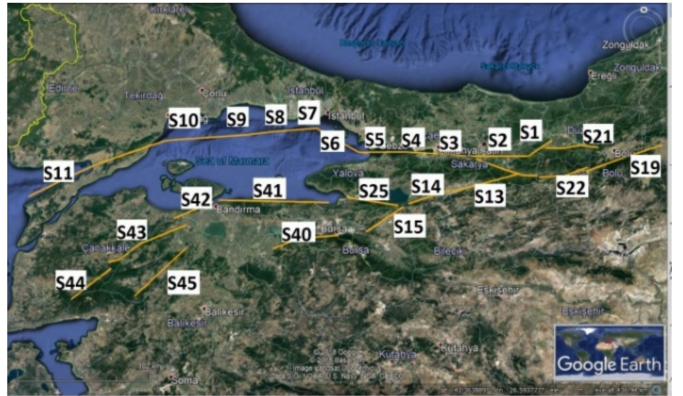

(c)

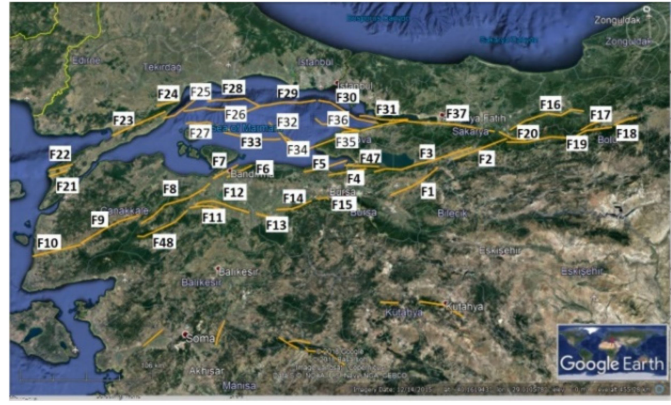

(d)

Figure 2. Source models developed for Marmara region: (a) [8] model 1, (b) [8] model 3, (c) [9], and (d) [10].

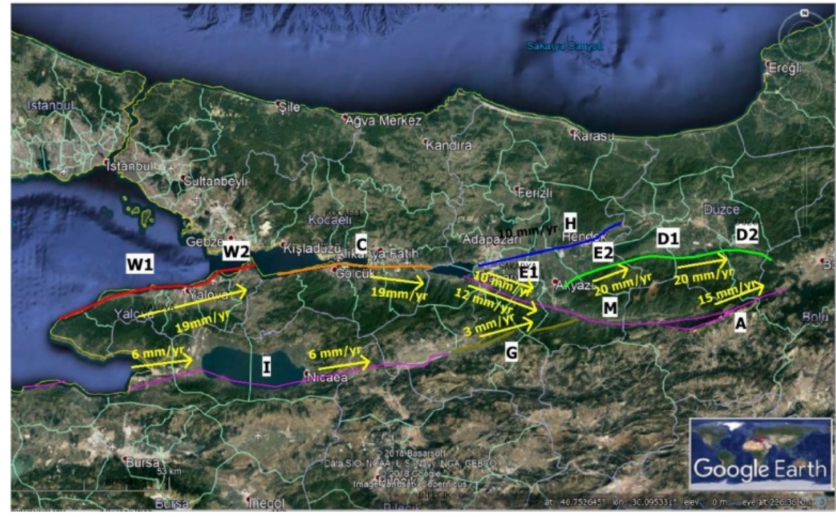

Figure 3. Source model of [11] for eastern Marmara region.

At ground motion prediction level, all studies differed in their choice of models and associated logic tree structure. Atakan et al. [8] adopted the models by [22-25], providing results separately for each model. Erdik et al. [9] combined three different models from [23-25] in a logic tree structure assigning equal weights to each branch. Kalkan et al. [10] used three NGA-W1 models, [26-28] and a regional model [29] setting the weight of the latter equal to the total weight of the NGA branches. Gülerce and Ocak [11] opted for five NGA-W1 models [26-28,30,31] and assigned equal weights to each in the logic tree.

All studies provided mean hazard maps corresponding to specific return periods for their respective study regions. However, the comparison of estimated hazard values is not straightforward due to presentation preferences of each study. It might be easier and more indicative to compare 475-year PGA for two sites, Izmit and Istanbul city centres, as the former is a site close to a recent fault rupture and the latter is close to expected near future ruptures. Table 1 provides a summary of results for PGA corresponding to 475-year return periods for these two cities as obtained from the four models mentioned above. As observed from these results, a large epistemic uncertainty prevails in the PSHA studies, even in the case of data availability and similarity of modelling preferences.

Table 1. Comparison of the 475-year PGA estimations by previous studies.

\begin{tabular}{|c|c|c|c|c|}
\hline \multirow[b]{3}{*}{ Model } & \multicolumn{4}{|c|}{ PGA 475 years } \\
\hline & \multicolumn{2}{|c|}{ Time Dependent Model } & \multicolumn{2}{|c|}{ Poisson Model } \\
\hline & Istanbul & İzmit & İstanbul & İzmit \\
\hline Atakan et al. [8] & \multicolumn{2}{|c|}{ Between $0.20-0.26$} & - & - \\
\hline Erdik et al. [9] & $0.45 \mathrm{~g}$ & $0.35 \mathrm{~g}$ & $0.37 \mathrm{~g}$ & $0.77 \mathrm{~g}$ \\
\hline Kalkan and Gülkan [10] & Between $0.30-0.40 \mathrm{~g}$ & Between $0.40-0.60 \mathrm{~g}$ & - & - \\
\hline Gülerce and Ocak [11] & - & - & - & $0.70 \mathrm{~g}$ \\
\hline
\end{tabular}




\section{Data Set}

In this section, we present a review of the recent activities towards the compilation of new and/or updated information regarding the two main data sets, namely the earthquake catalogue and the faulting data required for the development of the source models for the Marmara region. One of the major sources to this end was the databases compiled during the EU FP7 Marsite Project (http://marsite.eu)

\subsection{Earthquake Catalogue}

Earthquake catalogues are a compilation of earthquake events that have occurred in a region within a prescribed time period providing parametric data such as origin time, location, magnitude, and depth for each event. Thus, earthquake catalogues become the most crucial seismological product in regions such as Marmara Region, where earthquake hazard assessments exclusively rely on the analysis of historical and instrumental earthquake data.

In terms of both compilation and analysis methods, earthquake catalogues are investigated under two different time periods: the so-called historical one, usually corresponding to the pre-1900 period and going as back as possible in a reliable way and the so-called instrumental, corresponding to the post-1900 period. While compilations for the pre-1900 period rely mainly on macroseismic data, those of the post-1900 period are based mostly on instrumental information. Several recent global and regional compilations covering different time periods provide updated and/or reassessed seismicity data Turkey. Among these, four recent catalogues are: (1) SHEEC, the catalogue of historical earthquakes in Europe, for the period $1000 \mathrm{AD}$ to 1899 , which proposed a reassessment and homogenization of parametric information based on re-evaluation of macroseismic data in Europe and Turkey [32]; (2) GHEC, the Global Historical Earthquake Catalogue, which was compiled as a component of the Global Earthquake Model (GEM) initiative, providing parametric data for 825 earthquakes of the period 1000 AD to 1903 with a magnitude of $\geq 7.0$ and occasionally smaller ones [33,34]; (3) ISC-GEM Instrumental catalogue, which was another global component of the GEM initiative compiled by the International Seismological Centre (ISC) covering the period 1900 to 2009 and providing reassessed parametric information for earthquakes with magnitude $\geq 5.5$ [35]; (4) Kadirioğlu et al. [36] developed an updated earthquake catalogue for Turkey covering the period 1900 to 2012 and for earthquakes with magnitude $\geq 4.0$. The methodology of analysis consisted of the following steps: compilation of parametric data for the region between $32-45^{\circ} \mathrm{N}$ and $23-48^{\circ} \mathrm{E}$ from all available sources including seismological reports and literature; selection of preferred sources for each event; correction, if needed, of the epicentral coordinates in accordance with faulting data; and magnitude homogenization through conversion equations based on regional data.

The historical (pre-1900) period earthquake catalogue of the Marmara region, compiled within the scope of the EU FP7 Marsite Project, as well as several descriptive catalogues such as $[37,38]$ and parametric earthquake catalogues of [32-34] were consulted to obtain a catalogue of large magnitude historical events in the Marmara region. For the post-1900 period we have adopted the catalogue of [36], which was also declustered by the method of Gardner and Knopoff [39] for the removal of the dependent events (i.e., aftershocks). A catalogue of microseismic activity (Ml 0.5 to 5.5) for the period 2012-2016 was also compiled during the EU-FP7 Marsite Project.

Figure 4 presents the distribution of the large magnitude events $(\mathbf{M} \geq 6.6)$ while Figure 5 presents the entire seismicity catalogue used in the study. 


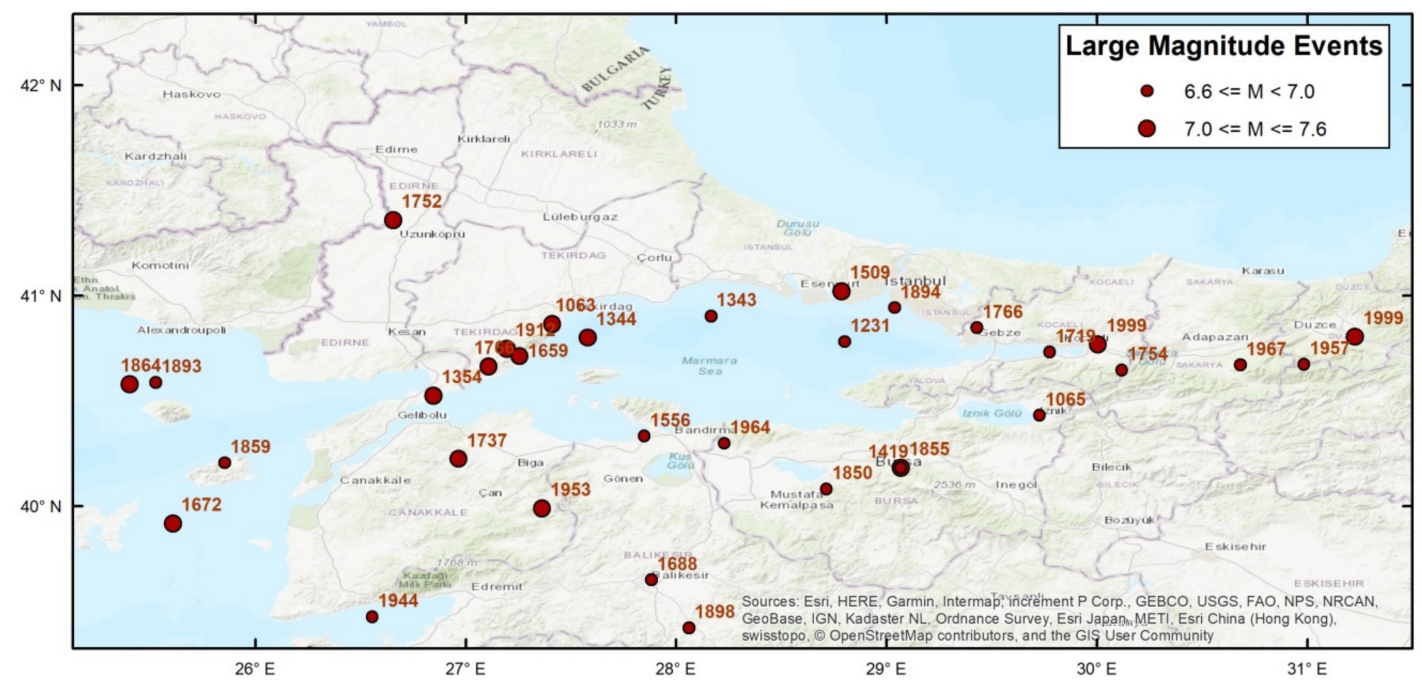

Figure 4. The distribution of the large magnitude events $(\mathbf{M} \geq 6.6)$.

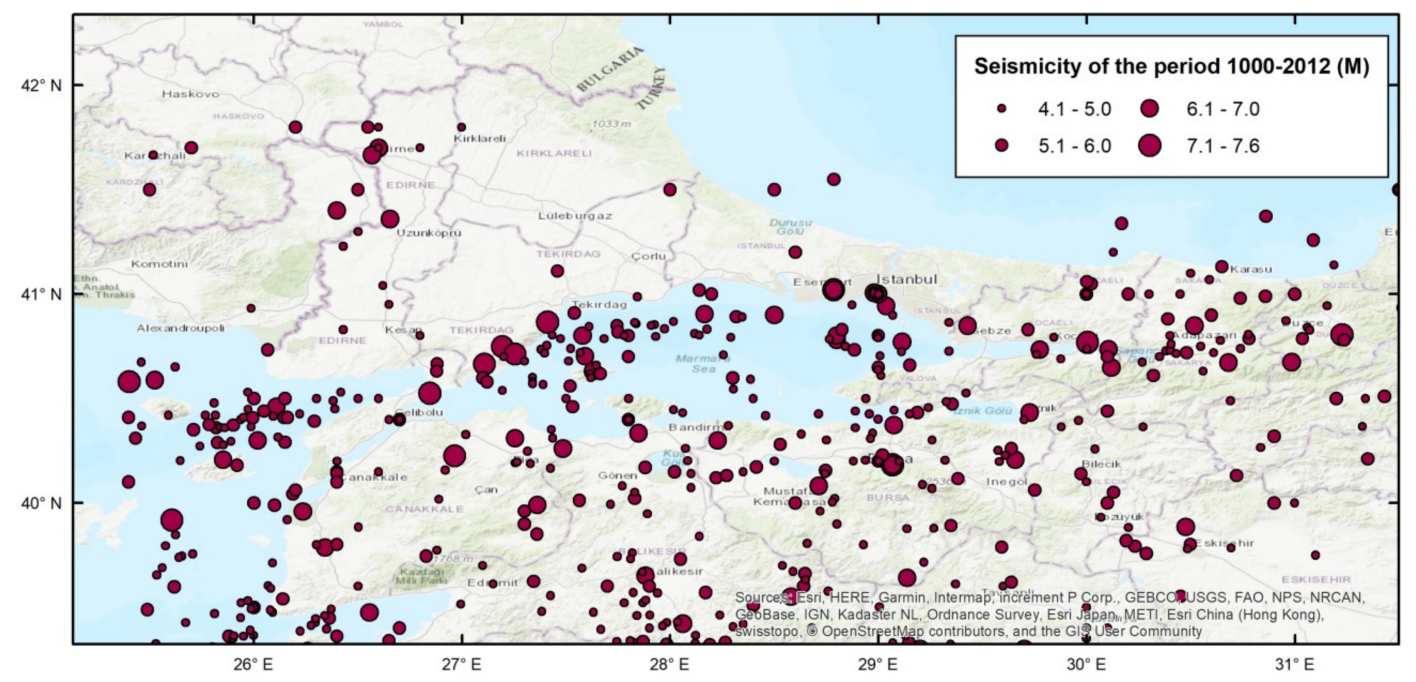

Figure 5. The earthquake catalogue of the region for the period 1000 AD to 2012.

\subsection{Fault Database}

The eastern part of the North Anatolian Fault Zone (NAFZ), extending from Erzincan to Bolu, consists of consecutive segments forming essentially a single trace, which has ruptured in four major earthquakes in the 20th century [40]. The fault structure becomes more complex to the west of Bolu. Here the main strand passes through the Mudurnu valley, the segments of which were ruptured in the 1957 and 1967 events. To the north of the same region, however, the Düzce segment forms another strand bounding the Bolu mountains in the north and connecting to the Izmit segment. Further to the west, as the North Anatolian Fault enters the Marmara region, it is again splayed into two main branches. The northern branch follows the Izmit segment, passing through the Izmit Bay where it enters the Marmara Sea. At the western exit of the Izmit Bay into the Marmara Sea, it forms a major trans-tensional NW-SE right-bend under the sea in the Çınarcık trough. From there on, the fault follows the northern margin of the Marmara Sea, paases the Central Marmara and Tekirdağ pull-apart basins, and connects to the NE-SW striking Ganos fault on land. Finally, this branch exits into the Aegean Sea through the Saros Gulf [41-47]. The southern branch of NAFZ, which splays from the main strand to the west of Mudurnu, runs on-land in the southern Marmara region, passing south of Iznik lake and the Gemlik Bay. It is composed of several parallel segments running southwest towards the Aegean Sea and bounding several quaternary basins [48]. 
The development of a segmentation model for a large fault zone is basically performed by geological considerations. Geometrical discontinuities such as restraining and releasing step-overs or bends, offsets and overlaps throughout the fault trace guide the development of the segmentation model which can also be constrained by observed displacements in recent earthquakes [48]. Following a critical review in terms of reliability and adaptability to seismic hazard assessment purposes, available segmentation models can be adopted for the development of a fault-based source model. While segment lengths of the model control the magnitude distribution, the slip rates on the faults, which are in fact subject to larger uncertainties, will dictate the recurrence. On the other hand, assigning historical earthquakes to particular fault segments introduces additional uncertainties as epicentral locations and magnitudes, and consequently fault ruptures associated with historical events are usually subject to major assumptions due to lack of data. This association on the other hand will both constrain the recurrence model of large earthquakes and, for the case of time-dependent assessments, impact the computation of the time elapsed since the last rupture of a given fault segment.

The segmentation model for the Marmara region defined here was based on the most recent and detailed data on the NAFZ branches available in the literature. In fact, one of the main datasets forming a basic input to the probabilistic seismic hazard model developed in this study was the fault database compiled in EU FP7 Marsite Project (Figure 6).

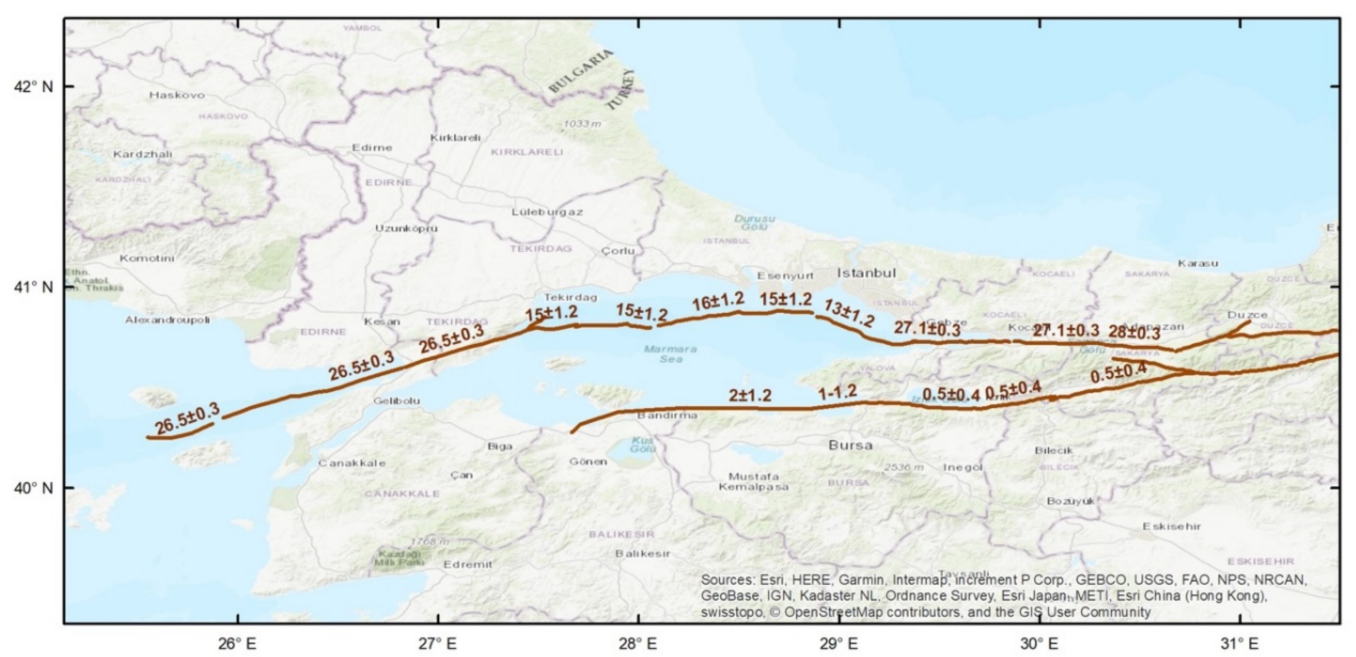

Figure 6. The active fault database compiled within the context of EU-FP7 Marsite project. Whenever available, the numbers on the fault segments indicate geodetic horizontal slip rates (in mm/year) as compiled by the project.

The fault data, including detailed geometry, mechanism and slip rates and associated uncertainties from the literature compiled in the Marsite Project were evaluated to obtain a fault source model to be used in the hazard analysis. In several cases, small segments, which we have interpreted as belonging to the same system, have been combined to obtain a fault source model suitable for the assessment of seismic hazard. We have complemented the model with segments of the Southern Marmara region, using data mostly from Emre et al. [49] (Figure 7). 


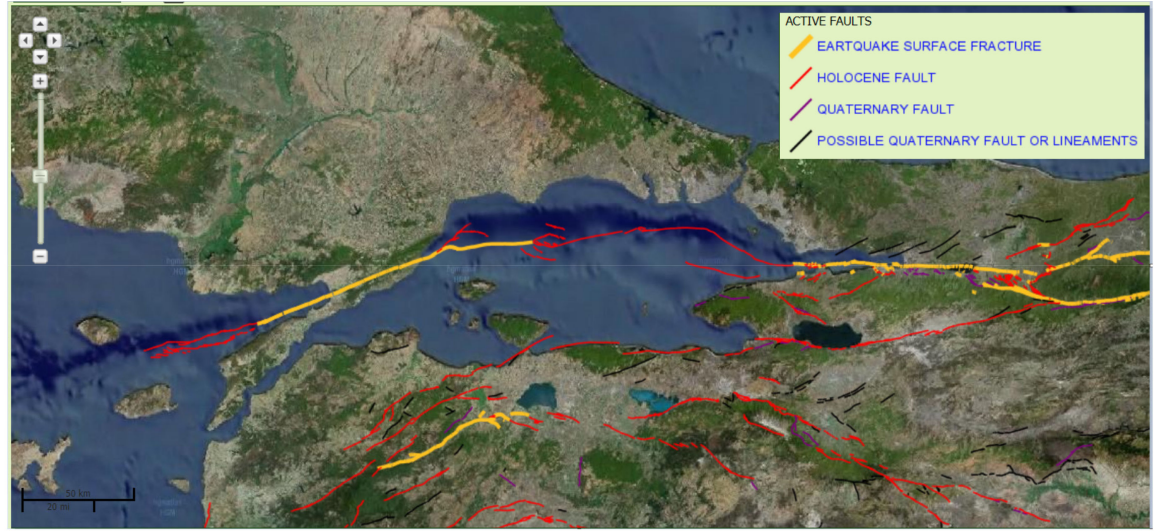

Figure 7. Regional active fault characterization by [49].

\subsection{The Fault Source Model}

In this study, we propose an updated fault segmentation model and associated parameterization for probabilistic seismic hazard assessment purposes based on recent studies of the NAFZ in the Marmara region integrating geometrical configuration of different segments with seismological data and recent estimates of the slip rates [5,6,43,50-53]. The model presented in Figure 8 incorporates three strands of the NAFZ in the Marmara region: the Northern one NNAF) traversing the Marmara Sea from Izmit Bay in the east to Ganos in the west, is the most active strand with right-lateral slip rates of 14-24 mm/yr. The Central (CNAF) and Southern (SNAF) branches run in parallel, on-land south of the Marmara region, from west of Mudurnu to the Aegean sea. The CNAF branch shows about $5 \mathrm{~mm} / \mathrm{yr}$ of right-lateral deformation while the oblique right-lateral SNAF strand accommodates 2-6 mm/yr of dextral slip and up to $8 \mathrm{~mm} / \mathrm{yr}$ of dip slip [54,55]. In the present model, we have adjusted the slip rates on the three branches of NAFZ in Marmara region to balance the total slip rate in the region which is in the order of $24 \mathrm{~mm} / \mathrm{yr}$ [3]. As the CNAF and SNAF are a group of fault segments running in parallel, we split the total slip rate of the southern Marmara between the two southern strands based on conclusions made by Straub et al. [56], with the CNAF slightly faster ( 4-5 mm/yr) than the SNAF ( 2-3 mm/yr). The slip rates along the branches are later used to determine the return periods of the characteristic earthquakes on each segment. The geometric and kinematic characterisation of the segmentation model is presented in Table 2.

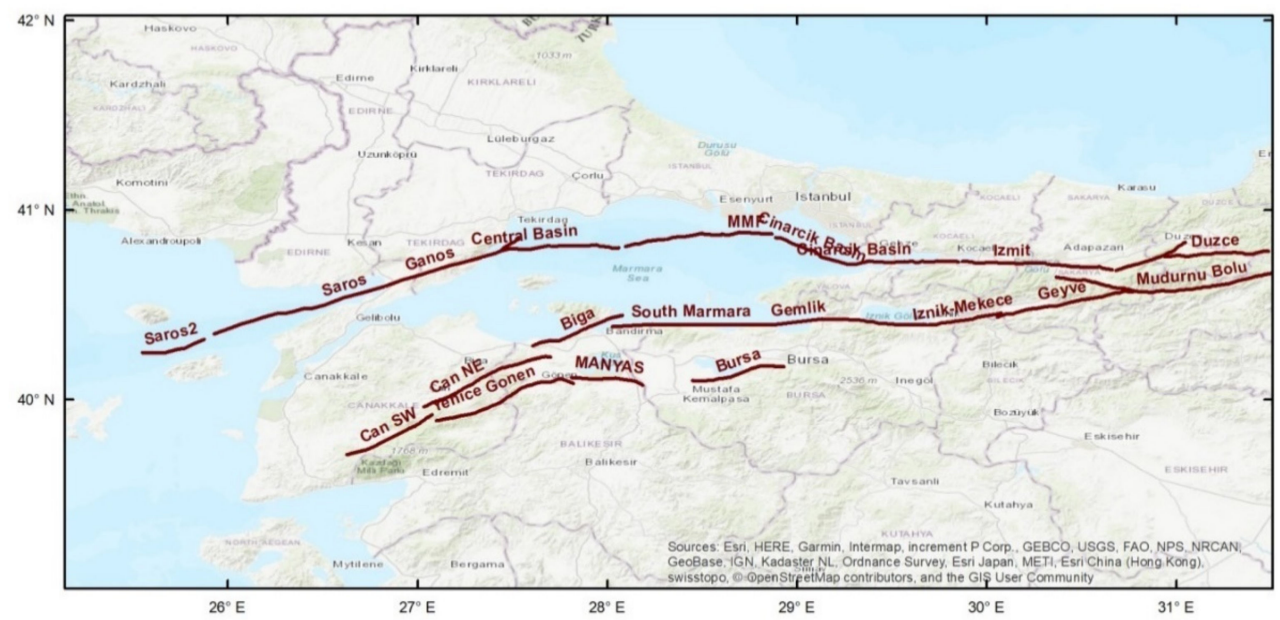

Figure 8. The fault source model developed in this study. The text indicates the segment names. 
Table 2. The fault source model and associated parameters.

\begin{tabular}{|c|c|c|c|c|c|c|}
\hline Segment Name & Length (km) & Width (km) & Dip Angle & $\begin{array}{l}\text { Slip Rate } \\
\text { (mm/yr) }\end{array}$ & Fault Type & $\begin{array}{c}\text { Associated } \\
\text { Historical Events }\end{array}$ \\
\hline \multicolumn{7}{|c|}{ Eastern Marmara Segments } \\
\hline Bolu East & 145 & 15 & 87.5 & 23.5 & SSF & 1668,1944 \\
\hline Bolu & 37 & 15 & 90 & 10 & SSF & 1957 \\
\hline Mudurnu & 67 & 15 & 87.5 & 10 & SSF & 1967 \\
\hline Duzce & 47 & 15 & 87.5 & 15 & SSF & 1999 \\
\hline \multicolumn{7}{|c|}{ Northern Branch Segments } \\
\hline Izmit & 144 & 15 & 87.5 & 20 & SSF & 1719,1999 \\
\hline Cinarcik Basin & 46 & 15 & 70 & 14 & NSSF & $1231,1754,1894$ \\
\hline MMF & 66 & 15 & 87.5 & 18 & SSF & 1509,1766 \\
\hline Central Basin & 54 & 15 & 85 & 18 & NSSF & 1343 \\
\hline Ganos & 66 & 15 & 82.5 & 19 & SSF & $\begin{array}{c}1063,1354,1766, \\
1912\end{array}$ \\
\hline Saros & 81 & 15 & 85 & 20 & SSF & 1859 \\
\hline Saros2 & 29 & 15 & 70 & 20 & SSF & 1912 \\
\hline \multicolumn{7}{|c|}{ Central and Southern Branch Segments } \\
\hline Geyve & 63 & 15 & 87.5 & 5 & SSF & 1296 \\
\hline Iznik-Mekece & 63 & 15 & 87.5 & 4 & SSF & 1419 \\
\hline Gemlik & 41 & 15 & 87.5 & 4 & SSF & 1855 \\
\hline South Marmara & 71 & 15 & 87.5 & 3 & SSF & 1556 \\
\hline Biga & 45 & 15 & 87.5 & 3 & SSF & 123 \\
\hline Can NE & 65 & 15 & 87.5 & 2 & SSF & 1737 \\
\hline Can SW & 46 & 15 & 87.5 & 2 & SSF & - \\
\hline Bursa & 43 & 15 & 87.5 & 3.5 & SSF & 1143 \\
\hline Manyas & 33 & 15 & 87.5 & 3 & SSF & 1964 \\
\hline Yenice-Gonen & 68 & 15 & 87.5 & 2 & SSF & 1953 \\
\hline
\end{tabular}

Another step of the model development, namely the association of historical and instrumental large magnitude earthquakes with the segmentation proposed for the three strands of the North Anatolian Fault in the Marmara region is shown in Figure 9 and also given in Table 2.

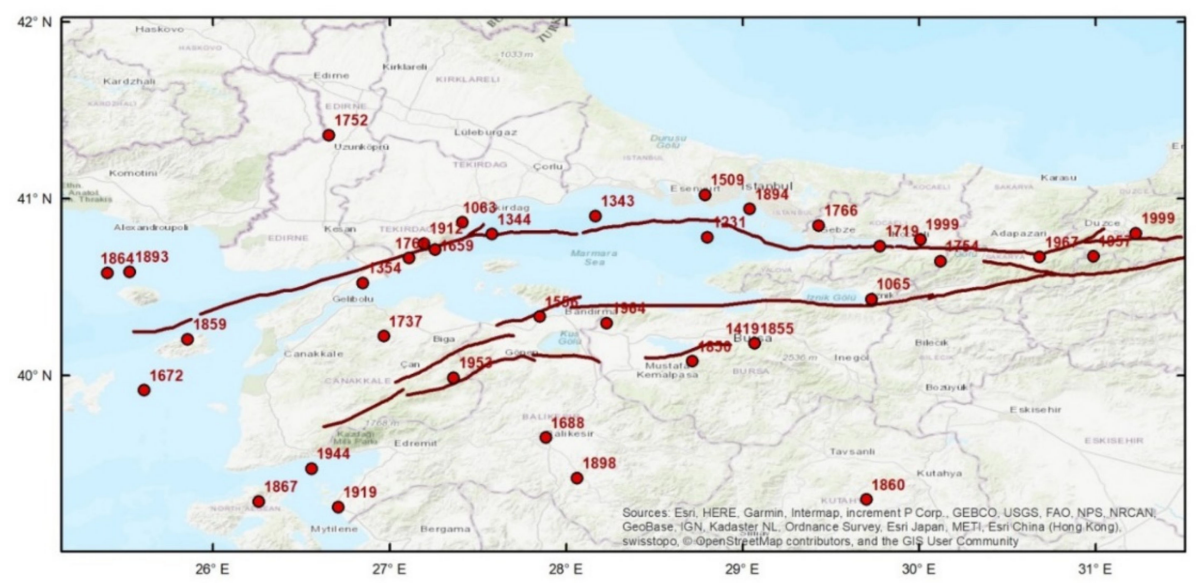

Figure 9. The association of historical and instrumental large magnitude earthquakes with the segmentation.

\section{Probabilistic Seismic Hazard Model and Methodology}

Following the PSHA studies conducted by $[9,10]$ for the Marmara region, in the present work we focus on the reassessment of the seismic hazard with the purpose of updating the hazard model using recently revised databases in the region. Earthquake rates are estimated through long-term earthquake recurrence behaviour of active faults as well as the spatial distribution of seismicity. Earthquake rate models are constructed following two earthquake source models:

(1) Seismicity-based source model: Following the spatially smoothed seismicity approach of [57], seismic activity rates of the so-called "gridded" sources are calculated from the "background source 
activity", i.e., small and intermediate size earthquakes (M4.3 to M6.6). This approach assumes that the small to moderate size activity is not necessarily associated with known faults and that the past distribution of seismicity will provide information about the location of future events [58]. Here the earthquake catalogue of the instrumental period is given precedence due to incompleteness and larger parameter uncertainty issues associated with the historical catalogues for the considered magnitude range.

(2) Fault-based source model: The earthquake recurrence rates for $\mathbf{M} \geq 6.7$ are calculated for the identified faults and fault segments based on a "characteristic earthquake" model. This model assumes that each fault ruptures with a characteristic earthquake [59,60], the magnitude of which is assessed from the fault dimensions and mechanism via empirical models. Long-term earthquake recurrence rate is estimated using the geologic slip rates on each fault. The cycle of earthquake occurrence and occurrence probabilities are then determined using both the time-independent (Poisson) and time-dependent (renewal) models. Finally, the rates of earthquakes on the fault systems and those of background seismicity are aggregated to determine the long-term earthquake rates as a function of magnitude in the Marmara region.

\subsection{Seismicity-based Source Model}

In this section, we develop the background-gridded seismicity model for Marmara region focusing on the spatial characterization of seismicity through the fixed smoothed seismicity approach as described by [57]. The source model assumes a magnitude-frequency distribution with the truncated form of the Gutenberg-Richter equation [61],

$$
\log 10 N(m)=\mathrm{a}-\mathrm{b} m
$$

where $N(m)$ is the number of earthquakes with magnitude $\boldsymbol{M} \geq m$, and the $b$-value is the slope of the magnitude-frequency distribution of seismicity within the magnitude completeness range. The seismicity rates are determined for a spatial grid of sources from the declustered earthquakes with $\mathbf{M}>4.3$ in the instrumental catalogue. This catalogue is assessed to be complete since 1900 for magnitudes greater than M5.3, since 1950 for magnitudes greater than M4.8, and since 1980 for magnitudes greater than M4.3.

We sub-divide the study area into a grid of $0.1^{\circ}$ by $0.1^{\circ}$ (about $10 \mathrm{~km} \times 10 \mathrm{~km}$ ) grid size. Then we calculate the number of earthquakes with magnitudes greater than or equal to $\mathbf{M} 4.3$ in each cell of the grid and rates are adjusted for variable completeness. Following the Gutenberg-Richter recurrence relationship [61], the $b$-value is calculated by maximum likelihood method proposed by [62], which considers the completeness periods of different magnitude bins. The $b$-value for the Marmara region is calculated as $0.87( \pm 0.03)$, using the completeness periods given above. The occurrence rate of magnitude $\mathbf{M}$ earthquakes, $\lambda_{i}$, in each $i$ th cell is calculated using $N$ events in the catalogue with the following equation;

$$
\lambda_{i}(m)=\sum_{j=1}^{N} K_{\sigma}\left(r_{i j}\right) R_{j}(\Delta t, M)
$$

where $K_{\sigma}, \sigma$, and $R_{i}\left(\Delta t, M_{\mathcal{c}}\right)$ are the smoothing kernel, smoothing distance or correlation distance, and event rates consider the magnitude completeness $M$ and completeness time $\Delta t$, and $r_{i j}$ is the distance between the $i$ th and $j$ th cell.

Finally, seismicity rates are smoothed adopting an isotropic, 2-D Gaussian function by the smoothing kernel:

$$
K\left(\mathrm{r}_{\mathrm{ij}}, \sigma\right)=\mathrm{C}(\sigma) \exp \left(-\mathrm{r}_{\mathrm{ij}}{ }^{2} / 2 \sigma^{2}\right)
$$

$K\left(r_{i j}, \sigma\right)$ is the smoothing kernel that is a function of distance, $r_{i j}$ and the smoothing or correlation distance $\sigma$. It is numerically integrated over each $i^{\text {th }}$ grid cell and normalized using the coefficient $C(\sigma)$. 
In this study, the smoothing distance is chosen as $25 \mathrm{~km}$ so that the earthquake rates are smoothed within a circle with radius not larger than $75 \mathrm{~km}$ or smaller than $25 \mathrm{~km}$. The small correlation distances present very grainy-looking maps and the larger ones produce much smoother one. One problem with the choice of the smoothing kernel is apparent in the NAFZ, where seismicity that occurs near and/or along the linear fault zones is over-smoothed. Figure 10 presents the gridded and smoothed $a$-values obtained for the study region. For the recurrence behaviour of the seismic activity, the time-independent Poisson assumption is preferred, such that the occurrence of an earthquake does not have any impact on the probability of occurrence for later events. In order to avoid double-counting of earthquakes in the hazard source model, maximum magnitude is set to M6.7 for the seismicity-based source model.

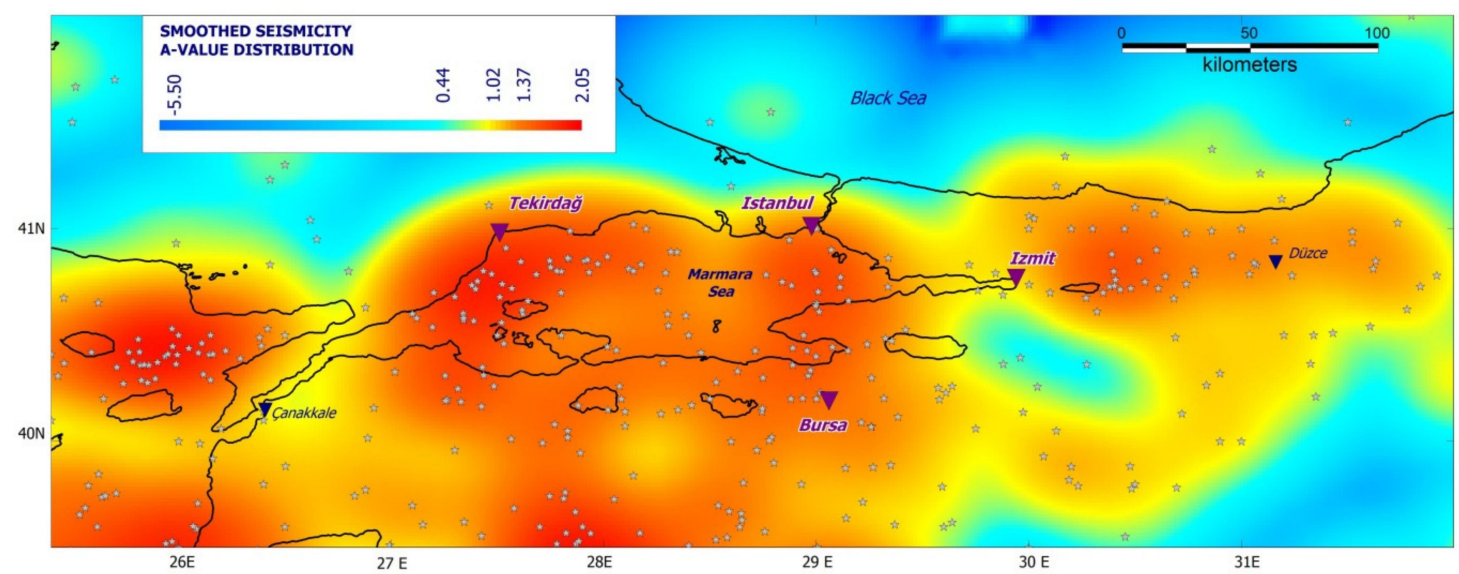

Figure 10. a-value distribution obtained with a smoothing kernel of $25 \mathrm{~km}$. Stars indicate the catalogue of the post-1900 period with $\mathrm{Mw}<6.8$.

\subsection{Fault-based Source Models}

In this part of the work, we exploit the geologic data sources to build-up a fault-based source model and associated recurrence for earthquakes of magnitude larger than M6.6 in the Marmara region. The long-term recurrence rate of each fault segment is estimated based on characteristic earthquake behaviour as presented by $[59,63]$. The characteristic magnitudes for the segments can be calculated through empirical relationships between magnitude and fault length or rupture area. The relationship between magnitude and fault area for strike-slip faults proposed by [63] is adopted here to obtain the mean characteristic magnitude for each segment of the source model (Table 3). With respect to the temporal modelling of the earthquake generation process, we assume fully characteristic earthquake occurrence on the faults and use two different approaches for earthquake rupture forecast: a time-independent (Poisson) model, in which the probability of occurrence of the characteristic event is uniform in time, and a time-dependent (renewal) model in which the probability of occurrence of the characteristic event varies depending on the time elapsed since the previous event. The slip rate along individual fault segments is the key parameter that controls the recurrence behaviour of the characteristic earthquakes both for the Poisson and time-dependent approaches. The elapsed time since the last characteristic earthquake will be the second key parameter in the calculation of future earthquake probabilities in the time-dependent model. 
Table 3. Mean return periods and annual rates of occurrence of characteristic earthquakes.

\begin{tabular}{|c|c|c|c|c|c|c|}
\hline $\begin{array}{l}\text { Segment } \\
\text { Name }\end{array}$ & $\begin{array}{c}\text { Area } \\
\mathrm{L}(\mathbf{k m}) \times \\
\mathrm{W}(\mathbf{k m})\end{array}$ & $\begin{array}{l}\text { Characteristic } \\
\text { Magnitude }\end{array}$ & $\begin{array}{l}\text { Slip Rate } \\
(\mathrm{mm} / \mathrm{yr})\end{array}$ & $\begin{array}{l}\text { Fault } \\
\text { Type }\end{array}$ & $\begin{array}{c}\text { Return } \\
\text { Period (yr) }\end{array}$ & $\begin{array}{c}\text { Annual } \\
\text { Rate } \\
\text { (Poisson) }\end{array}$ \\
\hline Bolu East & $145 \times 15$ & 7.5 & 23.5 & SSF & 130 & 0.00769 \\
\hline Bolu & $37 \times 15$ & 6.9 & 10 & SSF & 150 & 0.00667 \\
\hline Mudurnu & $67 \times 15$ & 7.2 & 10 & SSF & 235 & 0.00426 \\
\hline Duzce & $47 \times 15$ & 7.1 & 15 & SSF & 160 & 0.00625 \\
\hline Izmit & $144 \times 15$ & 7.5 & 20 & SSF & 155 & 0.00645 \\
\hline $\begin{array}{c}\text { Cinarcik } \\
\text { Basin }\end{array}$ & $46 \times 15$ & 7.1 & 14 & NSSF & 175 & 0.00571 \\
\hline MMF & $66 \times 15$ & 7.2 & 18 & SSF & 130 & 0.00769 \\
\hline $\begin{array}{c}\text { Central } \\
\text { Basin }\end{array}$ & $54 \times 15$ & 7.1 & 18 & NSSF & 115 & 0.0087 \\
\hline Ganos & $66 \times 15$ & 7.2 & 19 & SSF & 125 & 0.008 \\
\hline Saros & $81 \times 15$ & 7.3 & 20 & SSF & 140 & 0.00714 \\
\hline Saros2 & $29 \times 15$ & 6.8 & 20 & SSF & 70 & 0.01429 \\
\hline Geyve & $63 \times 15$ & 7.2 & 5 & SSF & 500 & 0.002 \\
\hline $\begin{array}{l}\text { Iznik- } \\
\text { Mekece }\end{array}$ & $63 \times 15$ & 7.2 & 4 & SSF & 625 & 0.0016 \\
\hline Gemlik & $41 \times 15$ & 7 & 4 & SSF & 480 & 0.00208 \\
\hline $\begin{array}{c}\text { South } \\
\text { Marmara }\end{array}$ & $71 \times 15$ & 7.2 & 3 & SSF & 750 & 0.00133 \\
\hline Biga & $45 \times 15$ & 7.1 & 3 & SSF & 825 & 0.00121 \\
\hline Can NE & $65 \times 15$ & 7.2 & 2 & SSF & 1200 & 0.00083 \\
\hline Can SW & $46 \times 15$ & 7.1 & 2 & SSF & 1200 & 0.00083 \\
\hline Bursa & $43 \times 15$ & 7.1 & 3.5 & SSF & 740 & 0.00135 \\
\hline Manyas & $33 \times 15$ & 6.9 & 3 & SSF & 565 & 0.00177 \\
\hline $\begin{array}{l}\text { Yenice- } \\
\text { Gonen }\end{array}$ & $68 \times 15$ & 7.2 & 2 & SSF & 1150 & 0.00087 \\
\hline
\end{tabular}

\subsubsection{Earthquake Rupture Forecast (ERF) Model: Poisson Approach}

As a first step to build the earthquake rupture forecast (ERF) model, the slip rates on the three branches of the North Anatolian Fault in Marmara region were adjusted to balance the total slip rate in the region which is about $24 \mathrm{~mm} / \mathrm{yr}$ (Table 3). Afterwards the long-term slip rates have been converted to earthquake recurrence rates for each fault segment conserving the seismic moment rate over each fault as proposed by [60]. The mean recurrence time (i.e. the return period) in years of the characteristic earthquake $\left(T_{r}\right)$ is computed as

$$
T_{r}=\frac{M o}{\mu x S R \times A}
$$

where $M o=10^{(1.5 M+9.05)}$ is the seismic moment corresponding to the characteristic earthquake, $\mu$ is the shear modulus of the ground ( $\mu=30 \mathrm{GPa}$ ), $S R$ is the long-term annual slip rate, and $A$ is the fault rupture area. The coefficients 1.5 and 9.05 (SI units) are suggested by [64]. The denominator of equation (4) represents the annual rate of seismic moment built-up. The return period of the characteristic earthquake is in fact the time in years that is required for the accumulation of the seismic energy (i.e., seismic moment) required for the characteristic to occur.

$\lambda_{\text {char }}=1 / T_{r}$ defines the mean annual occurrence rate of the characteristic earthquake. Following the Poisson assumption, the probability of occurrence of at least one earthquake on a fault segment within a time interval $\Delta T$ can be calculated with the following expression:

$$
P[N \geq 1]=1-e^{-\lambda_{\text {char }} \Delta T}
$$

In Table 3 we present the geometrical parameters and the mean characteristic magnitudes for each fault segment, the long-term geologic slip rates, the mean recurrence time (i.e., return period) 
and corresponding annual rates of occurrence for the characteristic earthquakes. Here we should mention that only mean slip rates are utilized for the computation of the mean recurrence times and that uncertainty on the slip rates may in fact cause variability in the recurrence parameter.

\subsubsection{ERF Model: Time Dependent Approach}

While the Poisson assumption is commonly used and well-accepted in the seismic hazard assessment practice, extensive paleo-seismic and historical seismicity investigations on individual faults suggest a rather periodic occurrence of large characteristic magnitude earthquakes providing the possibility to use time-dependent or renewal models for the hazard analysis [59]. Numerous statistical models have been developed for the calculation of the probability density function, such as Gaussian, log-normal, Weibull, Gamma, and Brownian Passage Time.

In the present work, we prefer the most frequently used Brownian Passage Time (BPT) probability model that is built on a straightforward physical model of the earthquake periodicity [65]. In BPT, the probability of an earthquake occurrence is conditional to the time elapsed since the last event, $t$, which can be given as:

$$
f\left(t, T_{r}, \alpha\right)=\left(\frac{T_{r}}{2 \pi t^{3} \alpha^{2}}\right)^{1 / 2} \exp \left(-\frac{\left(t-T_{r}\right)^{2}}{2 \alpha^{2} T_{r} t}\right)
$$

where $T_{r}$ is the mean recurrence time, and $\alpha$ is the aperiodicity. In this model, conditional probability of the next large earthquake varies with time. The elapsed time is set to zero upon the occurrence of each subsequent characteristic event. The occurrence probability of the next characteristic event is negligible right after the last event but starts increasing as the elapsed time since the last event increases. When the elapsed time since the previous earthquake is less than about $2 / 3$ of the estimated mean recurrence time, the BPT model predicts lower occurrence probability for the following earthquake compared to the Poisson model's one. After a certain point in time, the time-dependent model starts predicting higher probabilities compared to those of Poisson. The aperiodicity parameter ( $\alpha$ value) describes the regularity of the characteristic earthquake occurrences on any fault in time, smaller $\alpha$ values indicating more regularity in time. Therefore, the smaller the parameter $\alpha$, the higher will be the probability of occurrence of the next event for longer elapsed times with respect to the mean recurrence time. Generally, the aperiodicity parameter is determined from the coefficient of variation of actual observed recurrence times on active faults and well-built geological evidence [66]. When the historical and the paleo-seismological records are scarce, this parameter gets highly uncertain. In this study, due to a limited number of historical events associated with individual faults, the conditional probabilities are estimated assuming aperiodicity " $\alpha$ " value 0.5 as obtained by [66] through the statistical tests from the global earthquake recurrence times. These probabilities are conditional because they change as a function of the time elapsed since the last earthquake. Therefore, the conditional probabilities calculated by the BPT model are converted to effective Poisson rates (in our case $\Delta T$ is 50 years) through the following equation as proposed by $[67,68]$ :

$$
\lambda_{\text {eff }}=-\ln \left(1-\mathrm{P}_{\text {cond }}\right) / \Delta \mathrm{T}
$$

Table 4 shows the recurrence rates for each 21 faults calculated using the BPT model in the Marmara region. Some faults in Table 4 present larger elapsed time with respect to their calculated recurrence time. These values may have a major control on the earthquake occurrence probability estimations from the renewal models. Following this indication for the next 50 years, the largest time-dependent probabilities being more than $50 \%$ are found for the Central Basin, MMF, Ganos, Saros, and Saros 2 faults in the central and eastern part of the Marmara Sea region, close to the city of Istanbul (indicated in bold fonts in Table 4). The highest time-dependent probability value is calculated for the Saros 2 fault (being close to 80\%). This high probability results from the elapsed time (103 years), by its last characteristic event (1912), being well beyond the average recurrence time of 70 years (Tables 3 and 4). Similarly, the Central Basin and MMF faults show a high occurrence probability equal to $58.2 \%$ 
and 58.8\%, respectively (Tables 3 and 4). These faults also have long elapsed times (672 and 249 years) that are several times larger than their calculated inter-event times (130 and 115 years).

Table 4. Time-dependent 50-year probabilities and corresponding annual rates of occurrence of characteristic earthquakes.

\begin{tabular}{cccccc}
\hline $\begin{array}{c}\text { Segment } \\
\text { Name }\end{array}$ & $\begin{array}{c}\text { Annual Rate } \\
\text { (Poisson } \\
\text { Model) }\end{array}$ & $\begin{array}{c}\text { Last } \\
\text { Characteristic } \\
\text { Event }\end{array}$ & $\begin{array}{c}\text { Time Since } \\
\text { Last } \\
\text { Characteristic } \\
\text { Event }\end{array}$ & $\begin{array}{c}\text { 50 Year } \\
\text { Conditional } \\
\text { Probability } \\
\text { (Renewal) }\end{array}$ & $\begin{array}{c}\text { Annual Rate } \\
\text { (Renewal } \\
\text { Model) }\end{array}$ \\
\hline Bolu East & 0.00769 & 1944 & 71 & 0.45299 & 0.01207 \\
Bolu & 0.00667 & 1957 & 58 & 0.3042 & 0.00725 \\
Mudurnu & 0.00426 & 1967 & 48 & 0.05209 & 0.00107 \\
Duzce & 0.00625 & 1999 & 16 & 0.04992 & 0.00102 \\
Izmit & 0.00645 & 1999 & 16 & 0.05769 & 0.00119 \\
Cinarcik Basin & 0.00571 & 1894 & 121 & 0.39448 & 0.01003 \\
MMF & 0.00769 & 1766 & 249 & $\mathbf{0 . 5 8 1 8 6}$ & 0.01744 \\
Central Basin & 0.0087 & 1343 & 672 & $\mathbf{0 . 5 8 8 3 5}$ & 0.01775 \\
Ganos & 0.008 & 1912 & 103 & $\mathbf{0 . 5 4 5 5 8}$ & 0.01577 \\
Saros & 0.00714 & 1859 & 156 & $\mathbf{0 . 5 3 4 9 4}$ & 0.01531 \\
Saros2 & 0.01429 & 1912 & 103 & $\mathbf{0 . 7 9 9 6 9}$ & 0.03216 \\
Geyve & 0.002 & 1296 & 719 & 0.19793 & 0.00441 \\
Iznik- & 0.0016 & 1419 & 596 & 0.14505 & 0.00313 \\
Mekece & 0.00208 & 1855 & 160 & 0.04967 & 0.00102 \\
Gemlik & 0.00133 & 1556 & 459 & 0.0886 & 0.00186 \\
South Marmara & 0.00121 & 123 & 1892 & 0.12705 & 0.00272 \\
Biga & 0.00083 & 1737 & 278 & 0.00326 & 0.00007 \\
Can NE & 0.00083 & - & 1000 & 0.07225 & 0.0015 \\
Can SW & 0.00135 & 1143 & 872 & 0.13294 & 0.00285 \\
Bursa & 0.00177 & 1964 & 51 & 0.00005 & 0 \\
Manyas & 0.00087 & 1953 & 62 & 0 & 0 \\
Yenice- Gonen & & & & & \\
\hline & & & & & \\
\hline
\end{tabular}

Finally, combining the earthquake recurrence and ground motion occurrence models, the annual rate of exceedance of the ground motion parameter $u$, a certain value $u_{0}$, for a site, is calculated following [69]:

$$
\lambda\left(u>u_{0}\right)=\sum_{i} \lambda_{i}\left(m_{0}\right) \int_{m 0}^{m u} \int_{r} P\left(u>u_{0} \mid m, r\right) p_{i}(m) p_{i}(r) d r d m
$$

where $\lambda_{\mathrm{i}}\left(\mathrm{m}_{0}\right)$ is the recurrence rate of the $i$ source for $m \geq m_{0}$ earthquakes, ( $\lambda_{\text {cha }}$ and $\lambda_{\text {eff }}$ for the characteristic earthquake rates in case of the Poisson and renewal model); $m_{0}$ and $m_{u}$ is the lower and upper bound magnitude; $r$ is the distance between the source and the site; and $p_{i}(m)$, $p_{i}(r)$ are the probability density functions for earthquake magnitude and distance, respectively. $P\left(u>u_{0} \mid m, r\right.$ represents the ground motion estimation model for given magnitude $(m)$ and distance (r) pairs. In this study following Equation (9) we quantify the probability of exceeding various ground shaking levels on a grid of sites using the two distinct recurrence earthquake models together with the selected four GMPEs.

\section{Computation of The Seismic Hazard}

\subsection{Ground Motion Characterisation and Logic Tree}

Based on the evaluation of regional earthquake ground motion recordings and statistical ground motion prediction equation (GMPE) selection methods, [70] proposed an up-to-date logic tree for the characterisation of the ground motion in Turkey, which was later used in the update of the Turkish national seismic hazard maps [71-73]. As the main focus of the present study is an update of the source 
characterization in the Marmara region, we adopt for all source models (fault and background) the GMPE logic tree proposed by [70] for active shallow crustal regions, which consists of four models and associated weights as presented in Table 5.

Table 5. The active shallow crustal GMPE logic tree used in the present study.

\begin{tabular}{cc}
\hline Ground Motion Prediction Equation & Weight \\
\hline Akkar and Çağnan [74] (AC2010) & 0.30 \\
Akkar et al. [75] (ASB2014) & 0.30 \\
Chiou and Youngs [28] (CY2008) & 0.30 \\
Zhao et al. (2006) [76] (ZH2006) & 0.10 \\
\hline
\end{tabular}

The proposed GMPE logic tree presents a reasonable coverage of different models to capture the epistemic uncertainties in the ground motion characterization, including a local model [74], a regional model [75] and two global models [28,76] developed based on data from similar tectonic regimes. However as ground motion in the Marmara region corresponds only to a subsection of the Turkish data, to evaluate the applicability of the selected GMPEs, we compiled a set of recordings from recent earthquakes in the region and compared associated PGAs with selected models. The parameters and the epicentral locations of the selected earthquakes are presented in Figure 11. Corresponding ground motion parameters are obtained from the Earthquake Department of the Turkish Disaster and Emergency Management Authority (AFAD, https://deprem.afad.gov.tr).

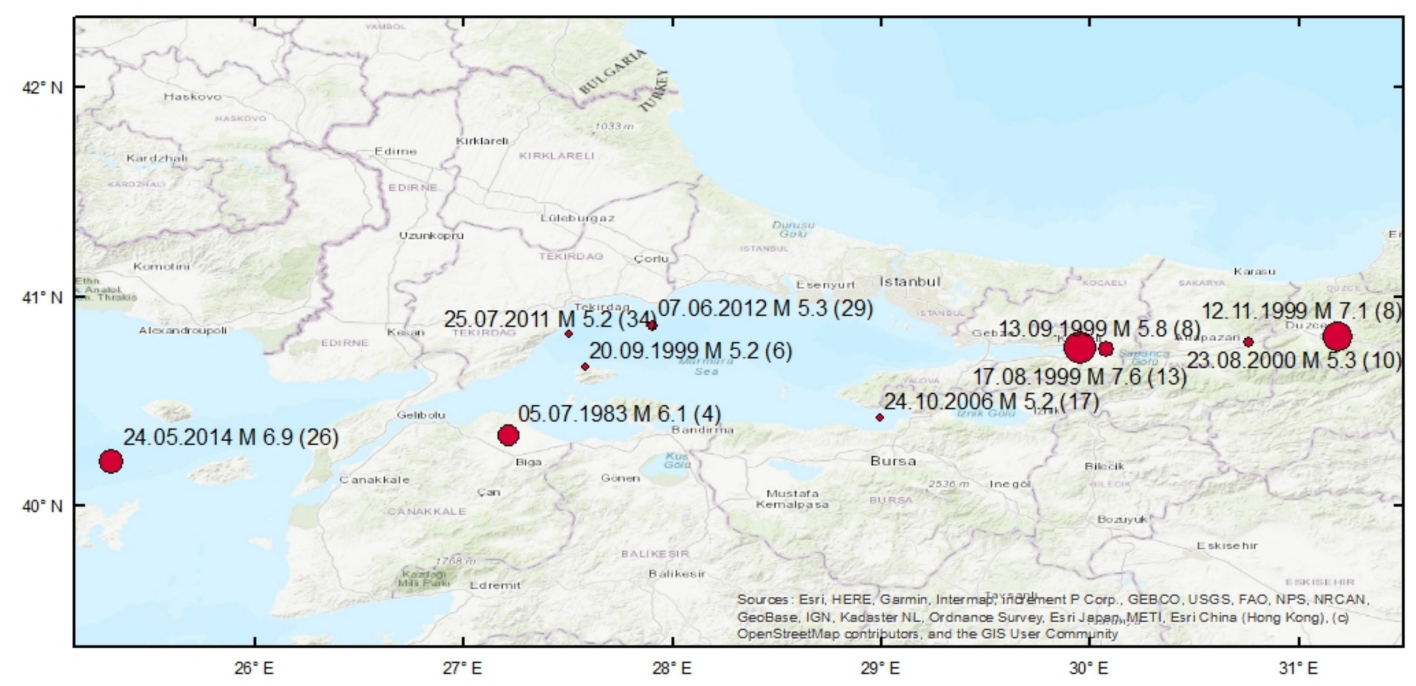

Figure 11. Earthquakes used to evaluate the applicability of GMPEs. Numbers in parentheses indicate the number of recordings for each earthquake within $250 \mathrm{~km}$ distance in our study region.

Figure 12 compares PGAs (geometric mean of the two horizontal components) from M5.2 earthquakes (the largest bin in our database), grouped in terms of site classes of the recording stations, with 16 (median-one standard deviation), 50 (median) and 84 (median + one standard deviation) percentile estimations of the four GMPEs used in the study. As all three models except ZH2006 use $\mathrm{V}_{\mathrm{s} 30}$ as a predictive parameter of the model; we used representative $\mathrm{V}_{\mathrm{s} 30}$ values of NEHRP site classes in the models and grouped the recordings accordingly. ZH2006 uses a site classification scheme slightly different to NEHRP and corresponding site coefficients in the model, which were also adopted in the corresponding plot. In Figure 13, we compare data from all earthquakes and all soil types with median estimations from the GMPEs for strike-slip faulting and a $V_{s 30}$ value of $510 \mathrm{~m} / \mathrm{s}$, which we considered representative for Site Class $C\left(V_{\mathrm{s} 30}\right.$ between 360 and $\left.760 \mathrm{~m} / \mathrm{s}\right)$. 


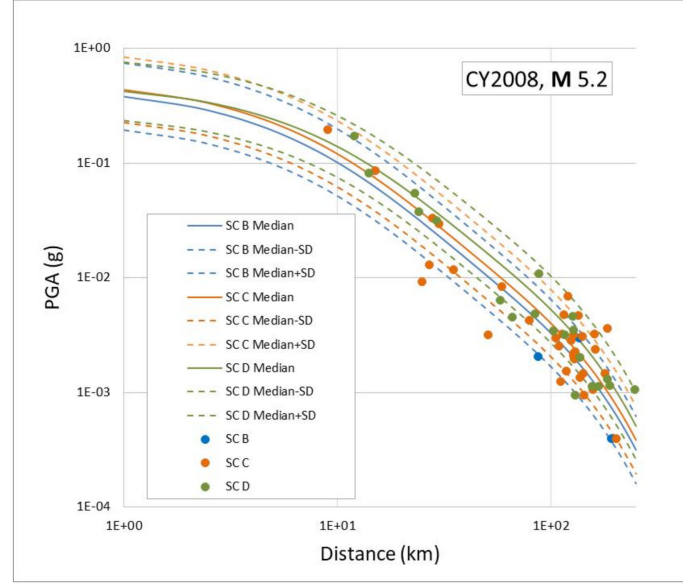

(a)

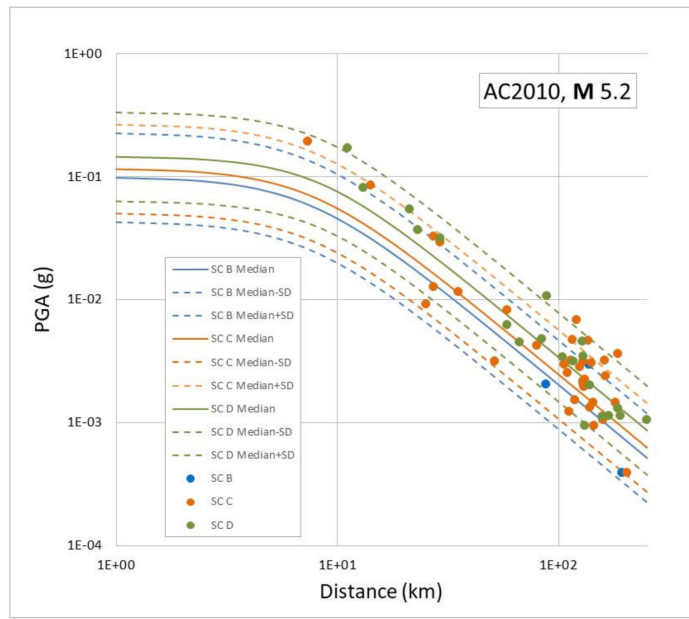

(c)

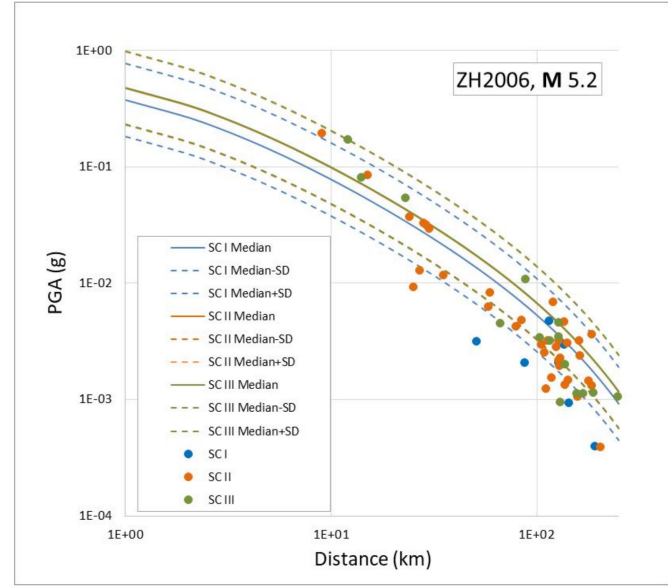

(b)

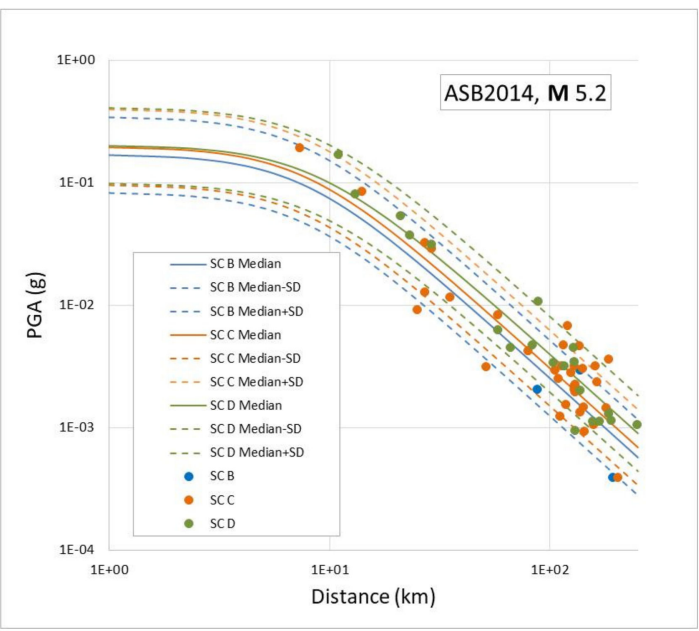

(d)

Figure 12. Comparison of the data from M5.2 earthquakes with the $16^{\text {th }}, 50^{\text {th }}$ (median) and $84^{\text {th }}$ percentile estimations from the four ground motion prediction models used in the GMPE logic tree: (a) CY2008, (b) ZH2006, (c) AC2010, (d) ASB2014.

Figure 12 reveals a satisfactory fit between the recorded ground motions and GMPEs for M5.2 earthquakes as almost all data remain within \pm standard deviation estimations for all models. When all magnitudes are considered (Figure 13), we observe a larger scatter with respect to the models, partly because here we compare all data with median estimations for a $V_{s 30}$ value of $510 \mathrm{~m} / \mathrm{s}$, but also for the following reasons: (a) the available distance parameter for the 24.05.2014 M6.9 earthquake is the epicentral distance, rather than distance to the fault rupture $\left(R_{r u p}\right)$ or Joyner and Boore distance $\left(R_{j b}\right)$ used in the models; and (b) data from the very large magnitude events of our database showed a large scatter with respect to distance and soil conditions. Overall, also considering that the aleatory variability up to three standard deviations from the median estimations are included in the computations, we conclude that the proposed GMPE logic tree structure satisfactorily covers the uncertainty in the ground motion occurrences in the Marmara region. 


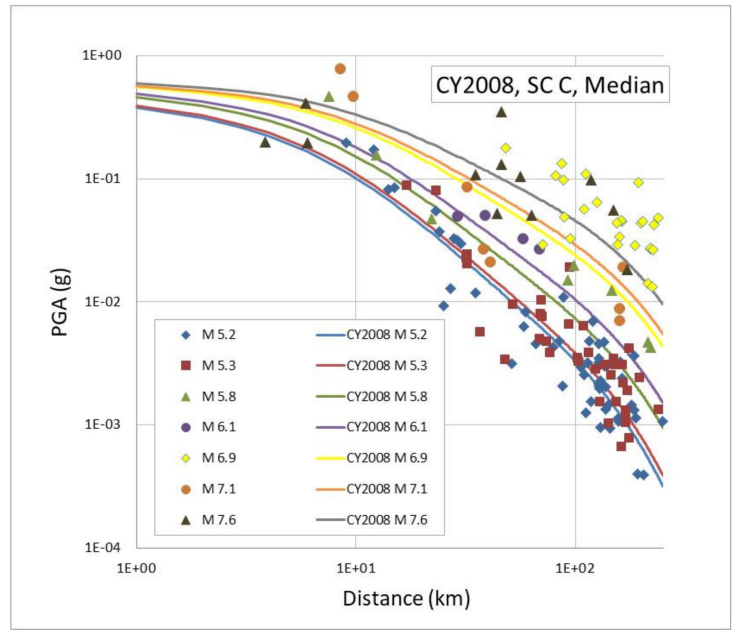

(a)

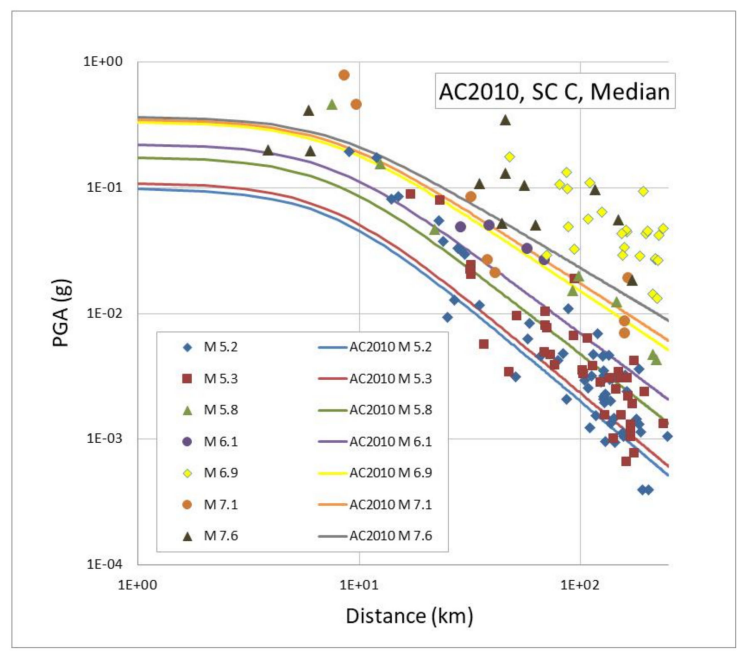

(c)

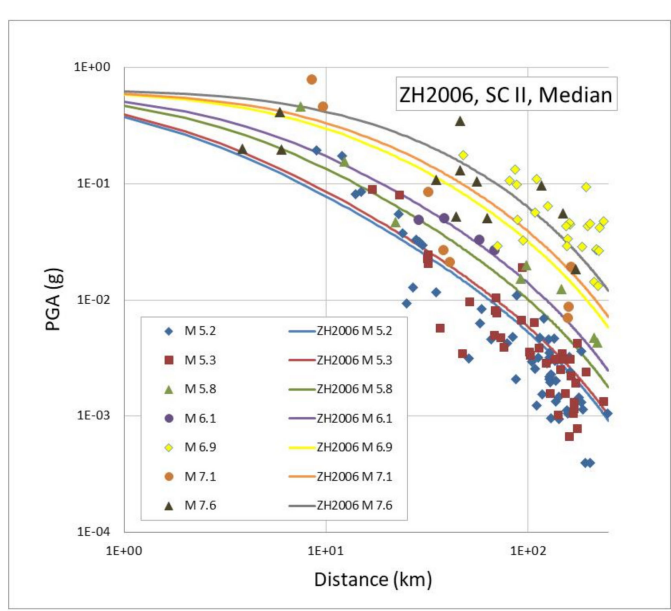

(b)

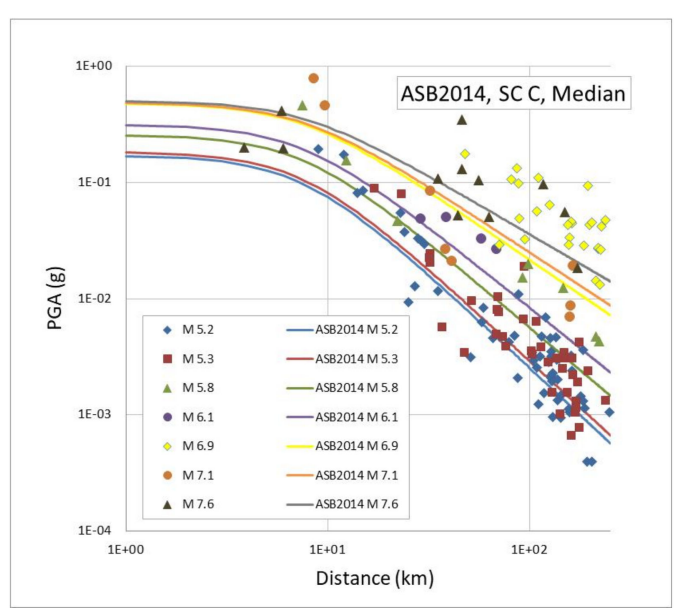

(d)

Figure 13. Comparison of all data from considered earthquakes with median, site class estimations from the four ground motion prediction models used in the GMPE logic tree: (a) CY2008, (b) ZH2006, (c) AC2010 (d) ASB2014.

\subsection{Computation of The Seismic Hazard}

We calculate the probability in 50 years of exceeding a various ground motion level at a series of gridded sites following the equation (8) using both time-independent and time-dependent models, together with the ground motion equations. We selected four GMPEs recently developed for the active shallow crustal regions and as selected by [70]. These GMPEs are integrated into the calculations using a logic tree model; three models [28,74,75] are assigned a weight of 0.3 each, while [76] is weighted by 0.1. In terms of the seismic source model, we integrated both smoothed background seismicity for earthquakes with magnitude below $\mathbf{M} 6.8$ ( $\mathbf{M}_{\min }$ being 4.3 ) and the geologically derived fault source model for earthquakes with $\mathbf{M} \geq 6.8$. The seismic hazard is calculated with two different approaches: (1) assuming a fully Poissonian earthquake occurrence for both the background seismicity and the fault sources; (2) assuming Poissonian occurrence at the background and a time-dependent earthquake occurrence on the fault sources. For hazard calculations, we used the Openquake software [19]. The gridded seismic sources have been modelled with the "point source" option while the linear sources have been modelled with the "characteristic fault source" option as provided in the Openquake platform. The present analysis has been conducted for the region bounded by $25.4-34.0^{\circ} \mathrm{E}$ and $39.2-42.0^{\circ} \mathrm{N}$ with a grid interval of $0.1^{\circ}$. The selected ground motion parameters of analysis were the 
Peak Ground Acceleration (PGA) and the 5\% damped Spectral Accelerations (SA) at periods of 0.2 and $1.0 \mathrm{sec}$ for engineering bedrock site conditions (average shear wave velocity of the upper $30 \mathrm{~m}$, $\mathrm{V}_{\mathrm{s} 30}$, of $760 \mathrm{~m} / \mathrm{s}$ ). The reasons for this selection are that PGA provides a quick perception of the hazard levels at the regional scale and is a convenient parameter for comparison with other studies, while spectral accelerations at periods of 0.2 and $1.0 \mathrm{sec}$ can be readily used to construct NEHRP type design spectra for any site. The outputs are mean hazard curves for each point of the grid for both the Poisson and time-dependent models complemented with the smoothed seismicity model for the background. Additionally, 475 and 2475 years ground motion distributions are extracted from the corresponding hazard curves.

\section{Results}

Here we present the PSHA results for the Marmara region corresponding to Poisson and time-dependent earthquake rupture forecast models, first in a set of ground motion intensity distribution maps; and second as hazard curves corresponding to four major cities, Istanbul, Izmit, Tekirdag, and Bursa (Figure 1) in our hazard model. All results correspond to engineering bedrock $\left(\mathrm{V}_{\mathrm{s} 30}=760 \mathrm{~m} / \mathrm{s}\right)$ site conditions.

\subsection{Hazard Maps for Selected Ground Motion Intensity Measures}

The seismic hazard at each point of our analysis grid is obtained from the contributions of (1) smoothed seismicity and characteristic fault ruptures with Poisson (time-independent) ERF or (2) smoothed seismicity and characteristic fault ruptures with time-dependent (renewal type) ERF. The contribution of these individual models to the final hazard can be observed in Figure 14 where we present, as an example, 475-year PGA distributions on bedrock resulting from background seismicity (Figure 14, upper panel) and the individual fault models using time-independent (Poisson) (Figure 14, central panel) and the renewal-BPT model (Figure 14, lower panel).

To further illustrate the effects of these individual contributions at different sites and ground motion intensity measures of different characteristics, we present in Figures 15 and 16 respectively, the seismic hazard curves for Istanbul, Tekirdağ, Bursa, and Izmit considering the Poisson, renewal-BPT and smoothed seismicity models for PGA and 5\% damped spectral acceleration (SA) at T $=1.0 \mathrm{~s}$.

Figure 14 reveals that for short period ground motions, background seismicity contributes significantly to the hazard particularly in the central Basin and Saros, in a few cases (southern strands of the NAF) it even alters the fault contributions, while the faults control the seismic hazard and ground motion parameters along the NAF zone. Note that the hazard calculated with both models (Poisson and BPT) shows considerable alterations and abrupt transitions along the north Anatolian fault zone.

On the other hand, looking at the individual hazard curves for short and mid-period ground motions (Figures 15 and 16 respectively), we observe that smoothed seismicity tends to govern the total seismic hazard for short return periods (up to around 72 years, $50 \%$ probability of exceedance in 50 years, or even higher) mainly for PGA at Bursa and Izmit, as the former is associated with very long return period faults, while the latter is close to a fault with very recent rupture. For mid-period ground motions on the other hand, fault contributions always govern the seismic hazard, as the effect of distant dominant sources becomes more significant than closer small sources for this type of ground motion parameter. 

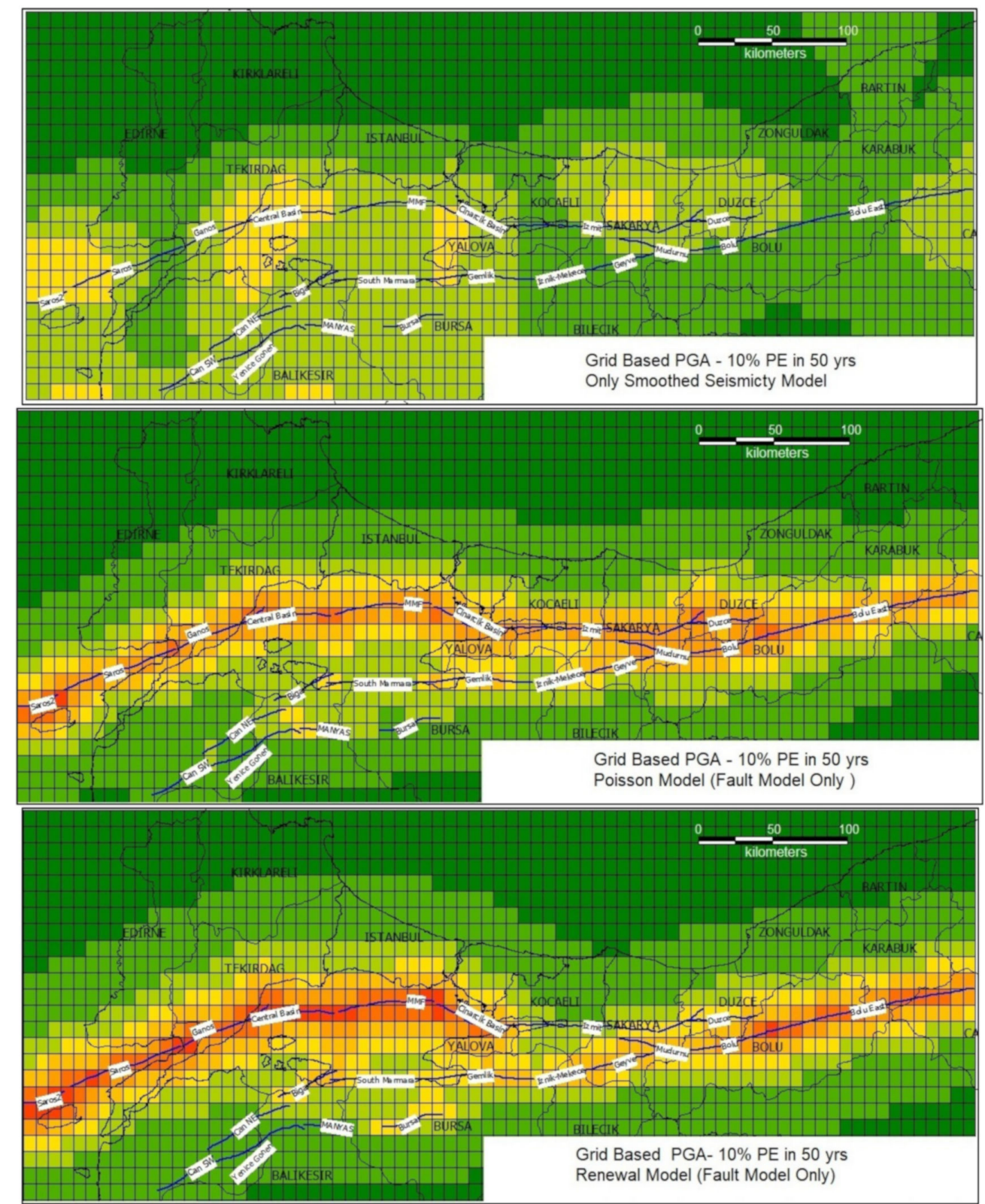

Unit, g

2 to $3.5 \square 1.5$ to $2 \square 1$ to $1.5 \square 0.8$ to $1 \square 0.6$ to $0.8 \square 0.4$ to $0.6 \square 0.3$ to $0.4 \square 0.2$ to $0.3 \square 0.1$ to $0.2 \square 0$ to 0.1

Figure 14. Probabilistic seismic hazard maps in terms of PGA (g) for rock site condition with $10 \%$ probability of exceedance in 50 years, derived from the seismicity-based source model (upper panel); fault-based source model with time-independent ERF (central panel) and the fault-based source model with time-dependent ERF (lower panel). 


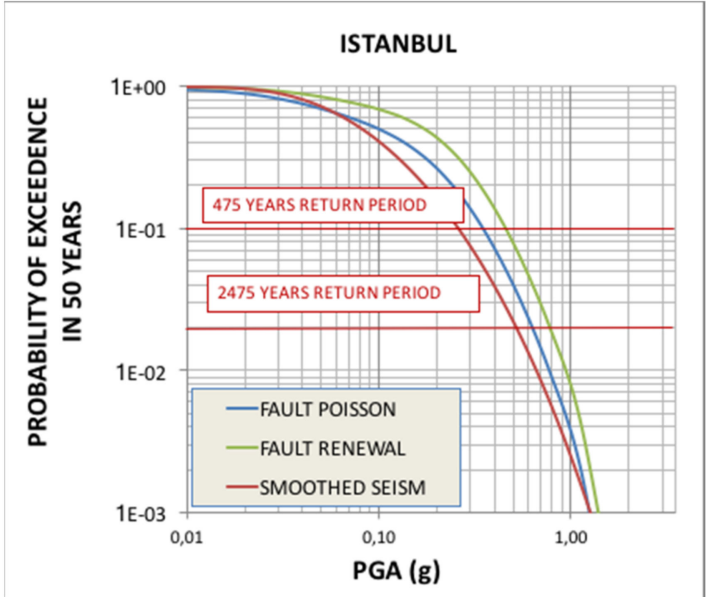

(a)

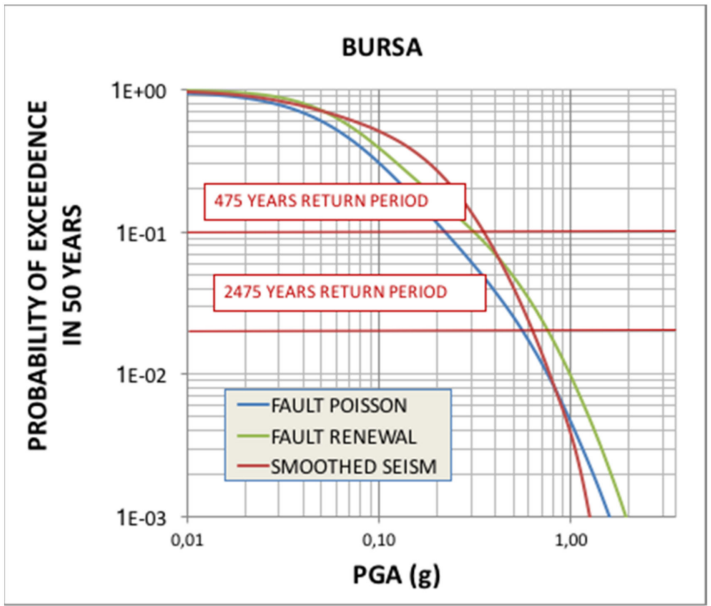

(c)

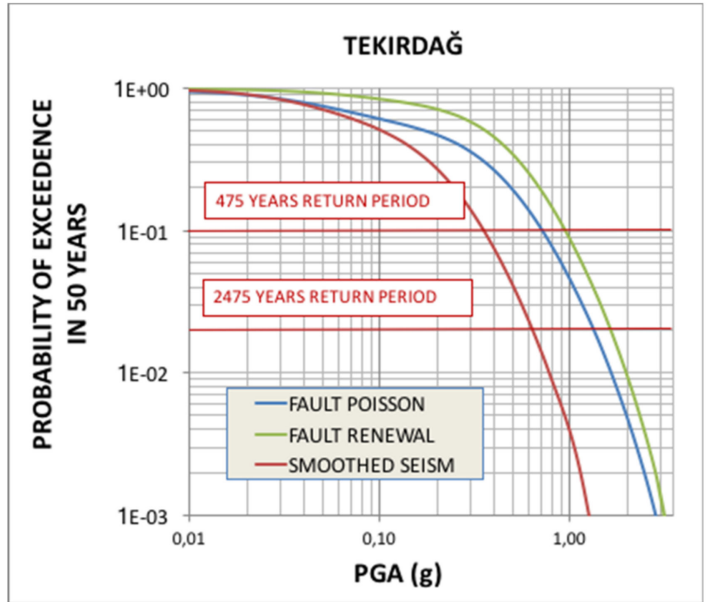

(b)

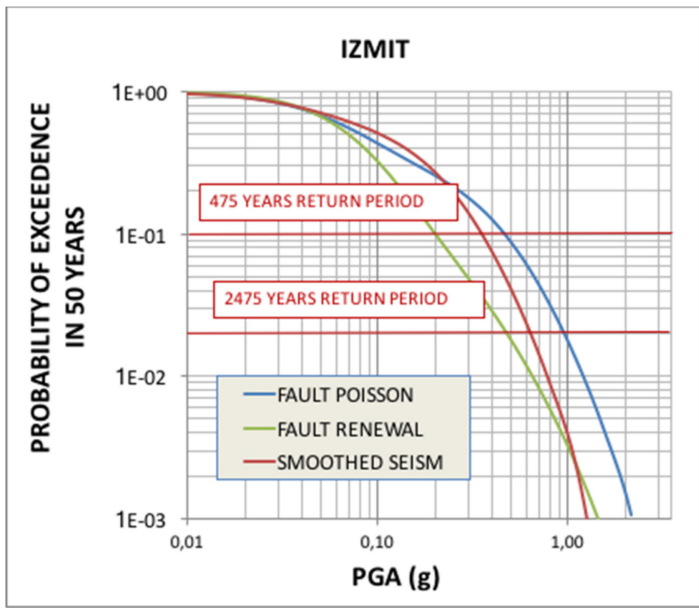

(d)

Figure 15. The PGA hazard curves for (a) Istanbul, (b) Tekirdağ, (c) Bursa, and (d) Izmit (Kocaeli) considering the individual Poisson, renewal-BPT and smoothed seismicity source models.

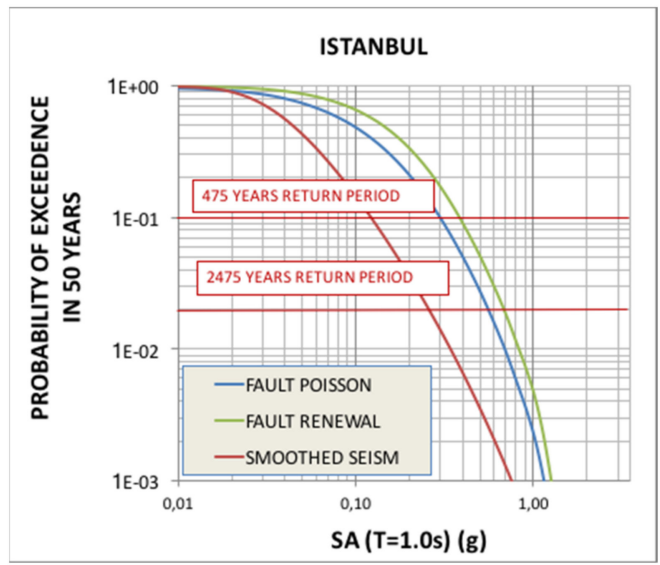

(a)

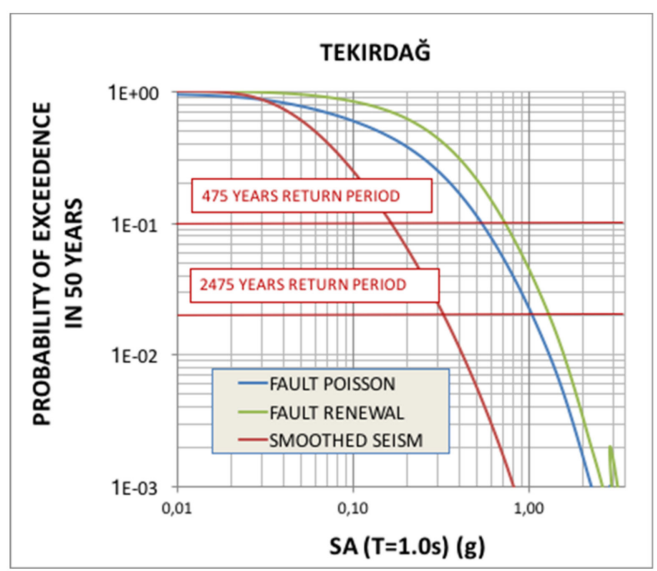

(b)

Figure 16. Cont. 


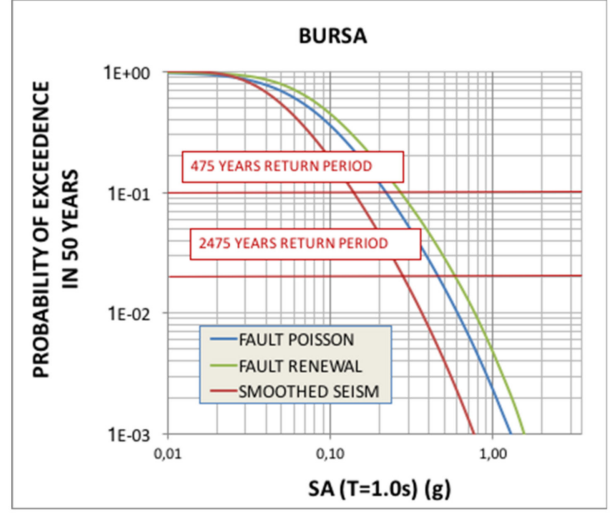

(c)

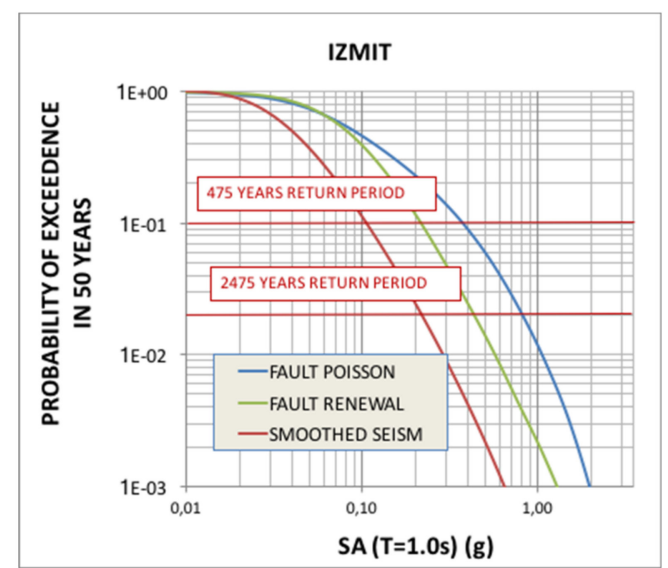

(d)

Figure 16. The $5 \%$ damped spectral acceleration (SA) at $\mathrm{T}=1.0 \mathrm{~s}$ hazard curves for (a) Istanbul, (b) Tekirdağ, (c) Bursa, and (d) Izmit (Kocaeli) considering the individual Poisson, renewal-BPT, and smoothed seismicity source models.

Final maps of mean PGA and 5\% damped horizontal spectral accelerations (SA T $=0.2 \mathrm{~s} \mathrm{~T}=1.0 \mathrm{~s}$ ) having $10 \%$ and $2 \%$ probability of exceedance in 50 years (associated with 475 and 2475 years return periods) on bedrock obtained from the background seismicity and the individual fault models based on time-independent (Poisson) and the renewal-BPT assumptions are presented in Figures 17-22. The time-dependent probabilistic seismic hazard maps result from the same GMPE logic tree as considered in the Poisson model and refer to $10 \%$ and $2 \%$ exceedance probabilities in the next 50 years.
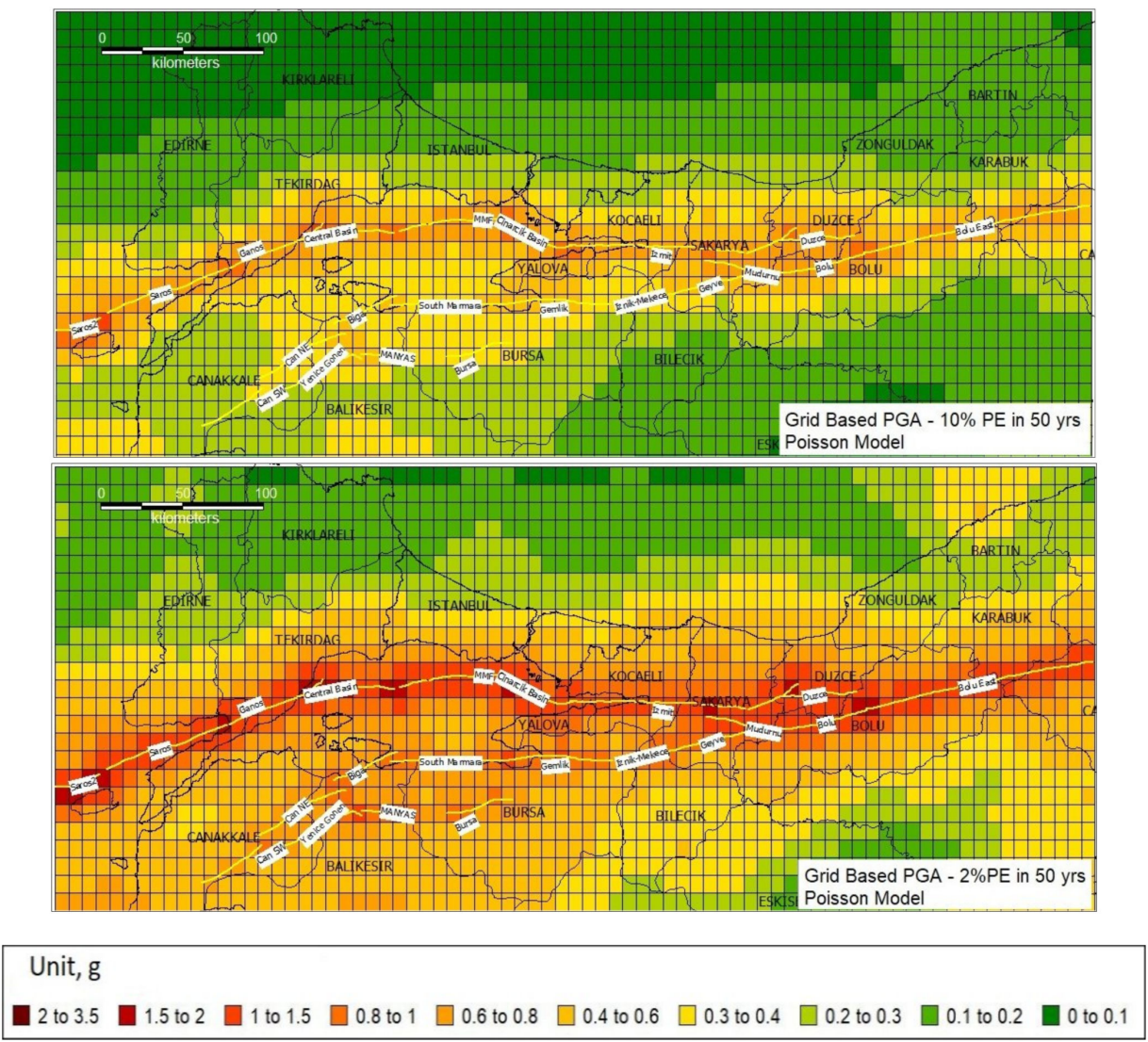

Figure 17. Grid-based PGA distribution at NEHRP B/C boundary site class for 10\% (upper panel) and $2 \%$ (lower panel) probabilities of exceedance in 50 years (Poisson model). 

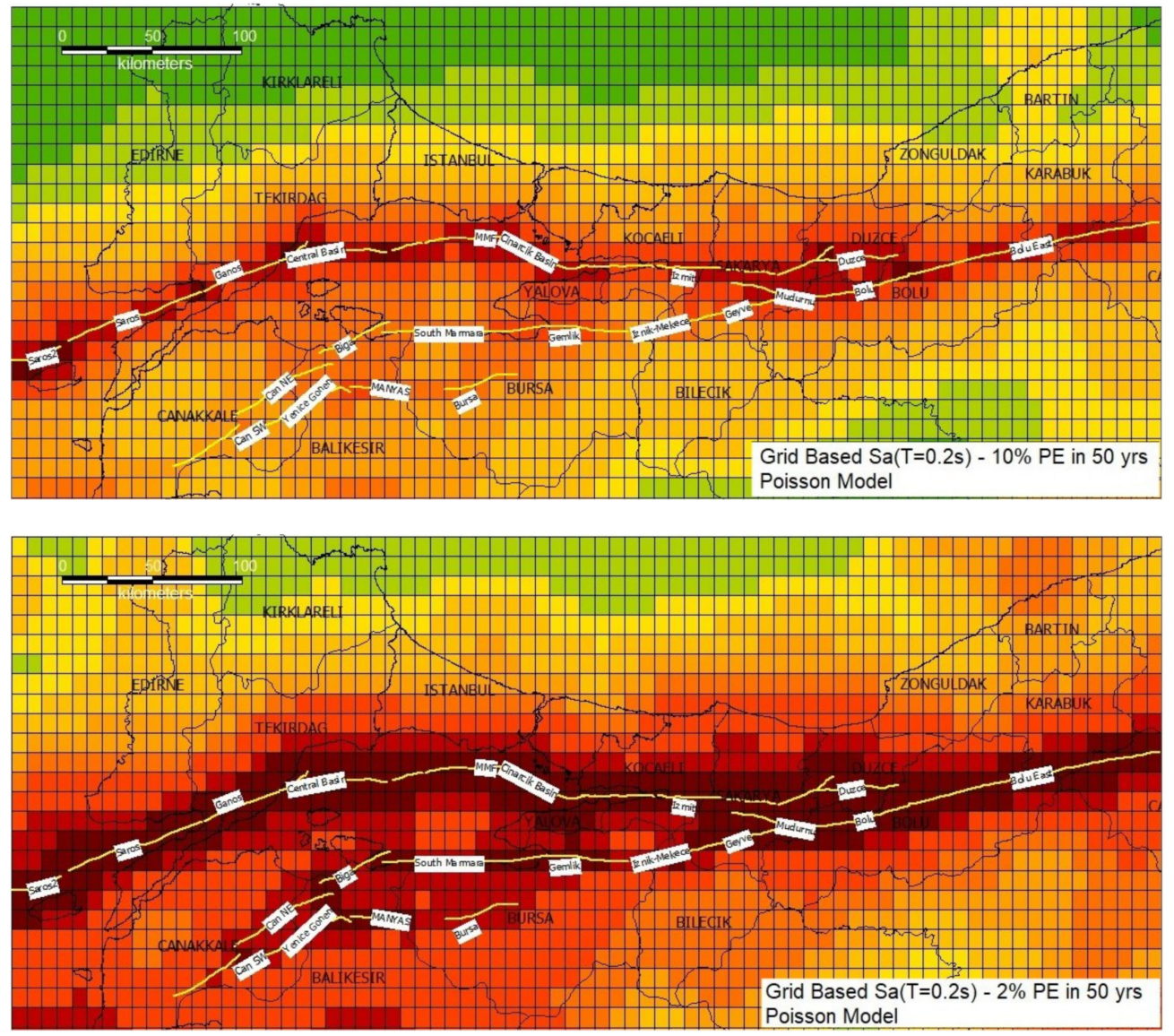

Figure 18. Grid-based SA $(T=0.2 \mathrm{~s}$ ) distribution at NEHRP B/C boundary site class for $10 \%$ (upper panel) and $2 \%$ (lower panel) probabilities of exceedance in 50 years (Poisson model). Color coding is the same as in Figure 17.

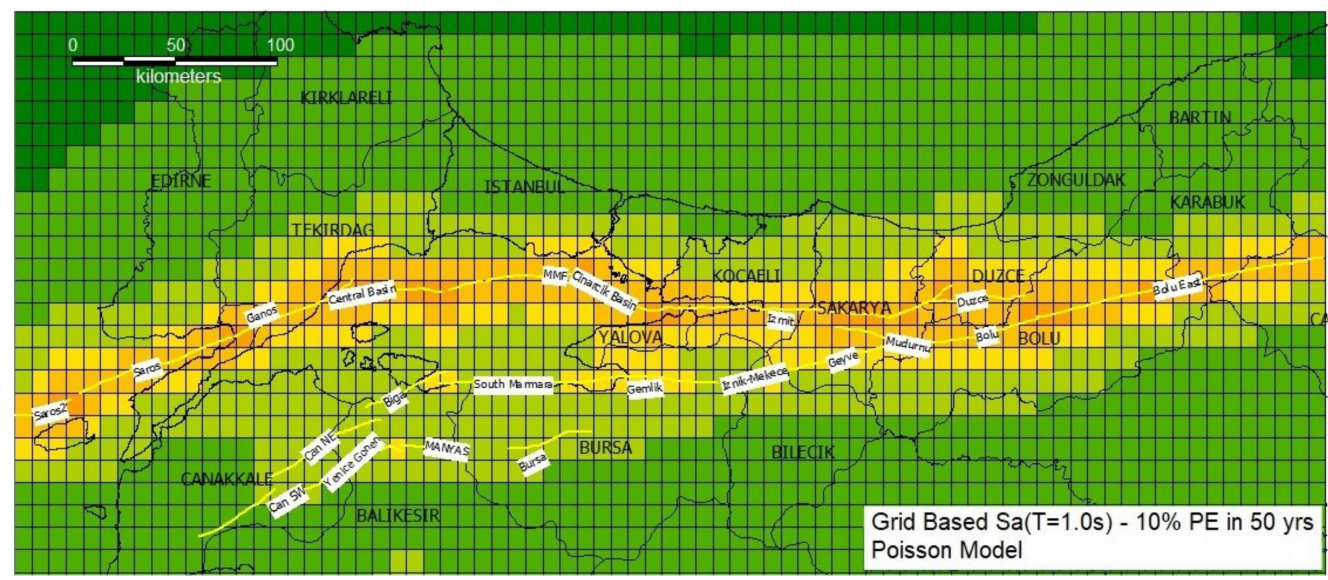

Figure 19. Cont. 


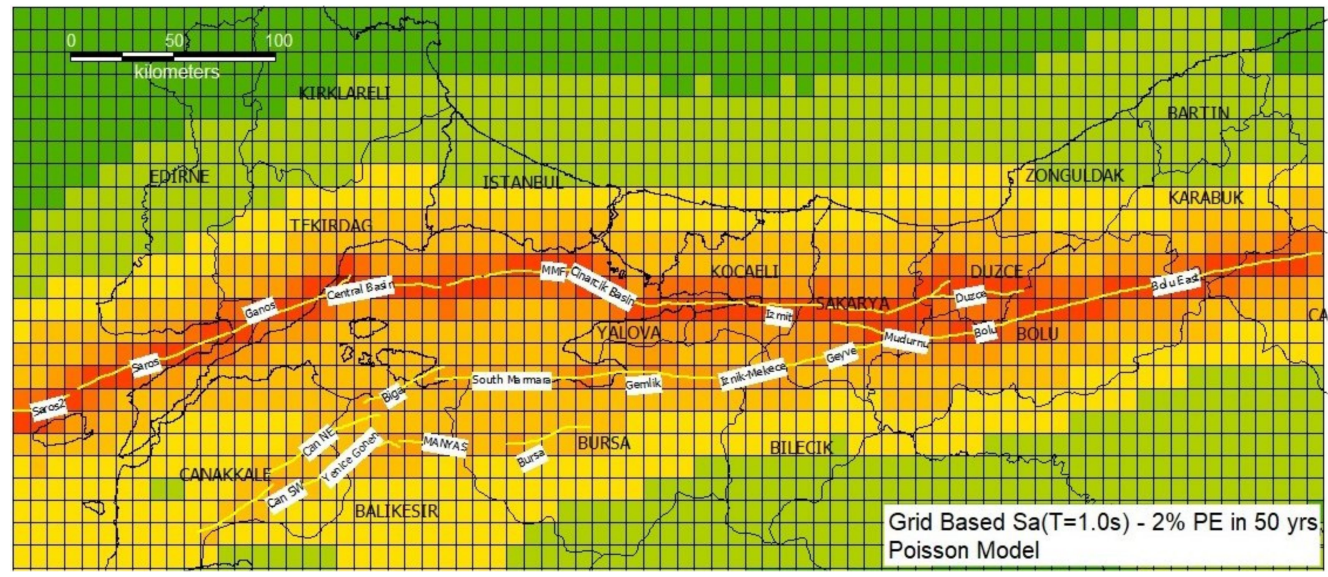

Figure 19. Grid-based SA $(\mathrm{T}=1.0 \mathrm{~s}$ ) distribution at NEHRP B/C boundary site class for $10 \%$ (upper panel) and $2 \%$ (lower panel) probabilities in 50 years (Poisson model). Color coding is the same as in Figure 17.
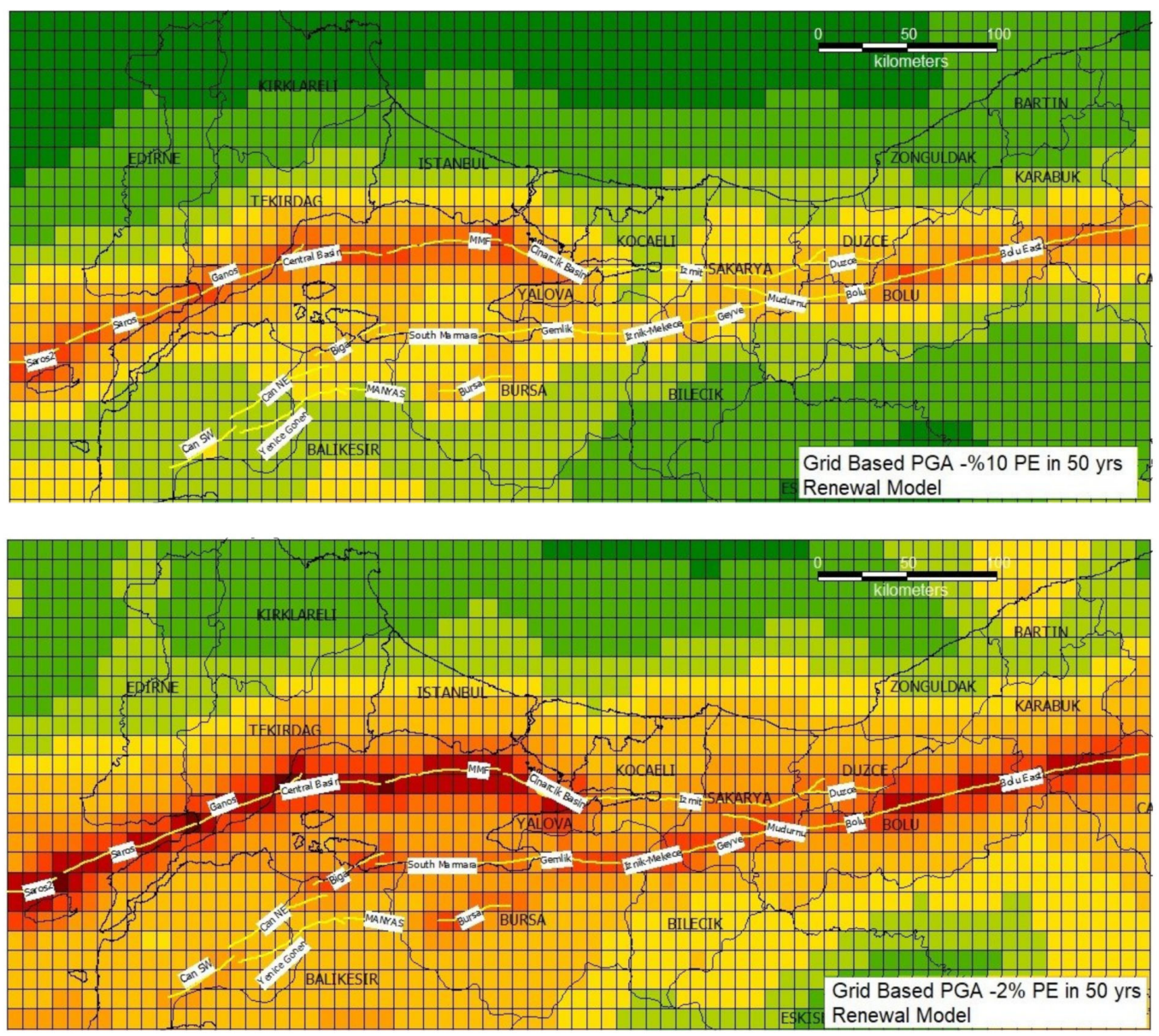

Figure 20. Grid-based PGA distribution at NEHRP B/C boundary site class for $10 \%$ (upper panel) and $2 \%$ (lower panel) probabilities of exceedance in 50 years (Renewal model). Color coding is the same as in Figure 17. 

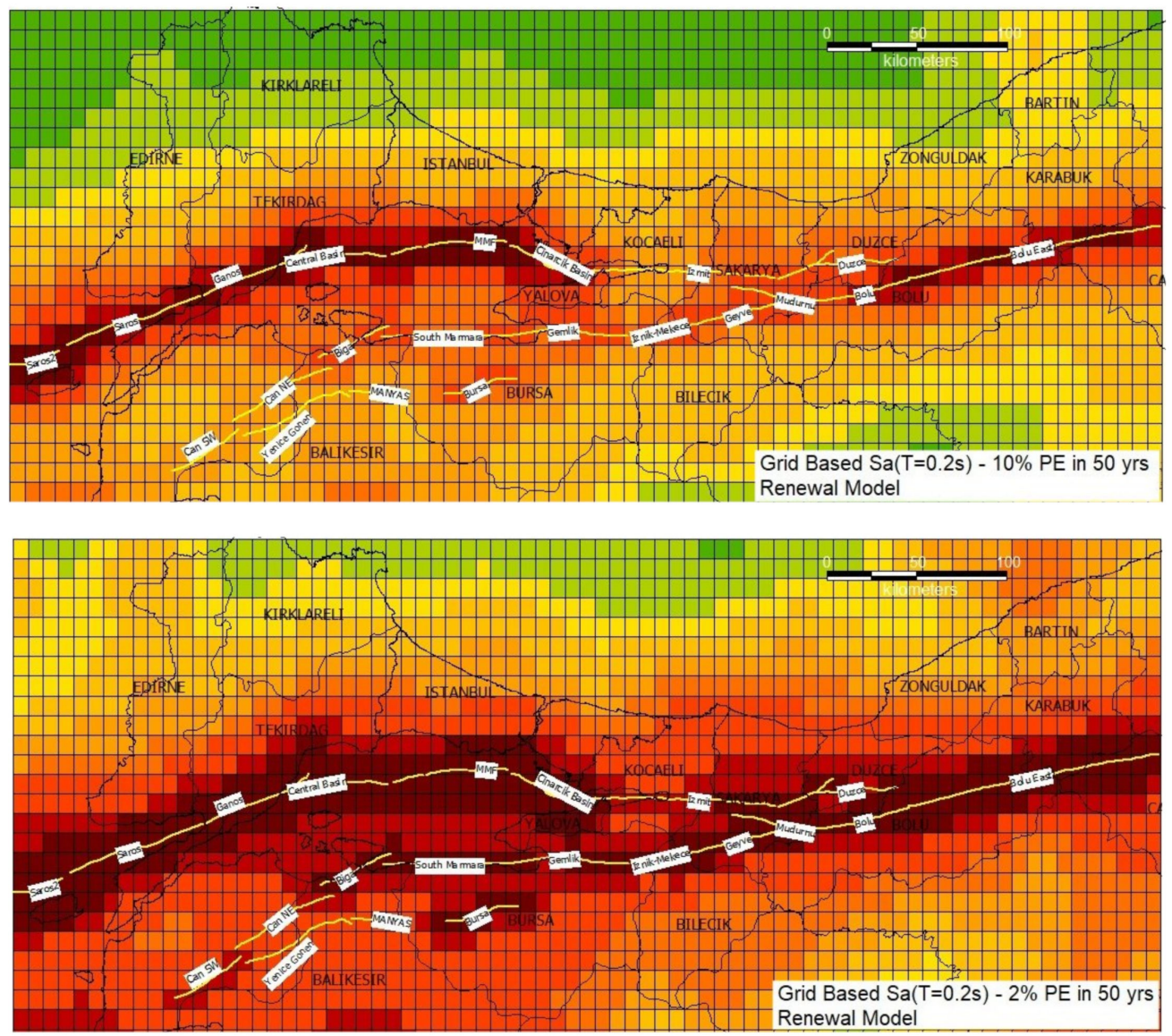

Figure 21. Grid-based SA $(T=0.2 \mathrm{~s}$ ) distribution at NEHRP B/C boundary site class for 10\% (upper panel) and $2 \%$ (lower panel) probabilities of exceedance in 50 years (Renewal model). Color coding is the same as in Figure 17.

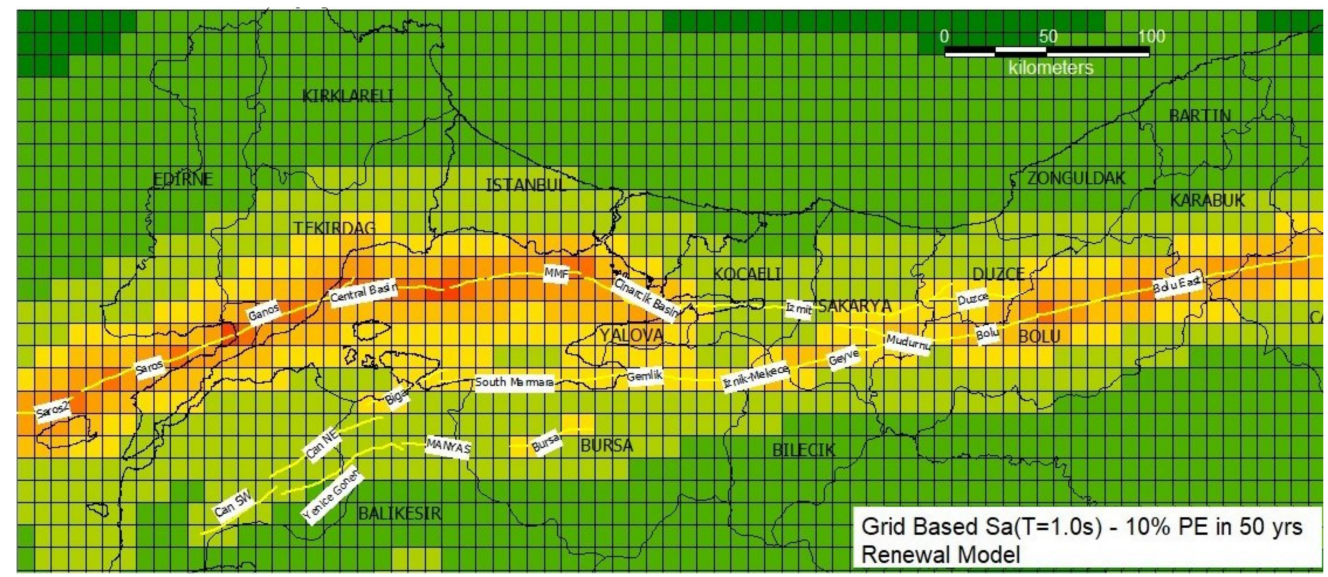

Figure 22. Cont. 


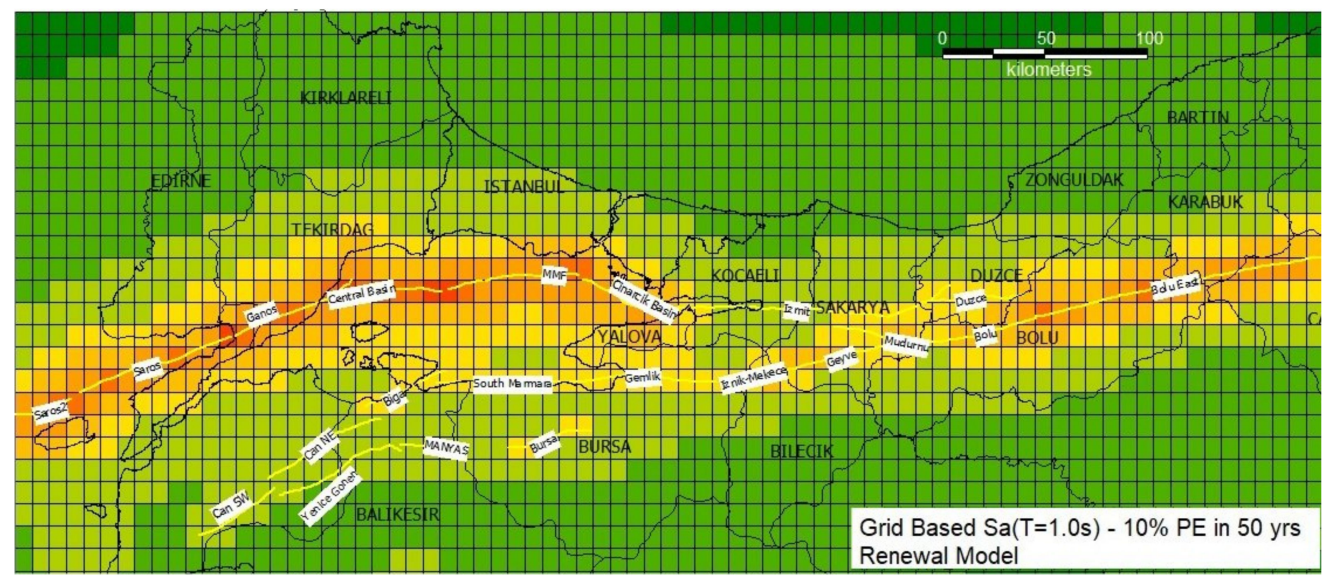

Figure 22. Grid-based SA ( $\mathrm{T}=1.0 \mathrm{~s}$ ) distribution at NEHRP B/C boundary site class for $10 \%$ (upper panel) and $2 \%$ (lower panel) probabilities of exceedance in 50 years (Renewal model). Color coding is the same as in Figure 17.

The standard time-independent seismic hazard map presents the highest hazard along the Northern strands of the North Anatolian Fault zone in the Marmara Sea and over the land sites like around the city of Izmit, Bolu and Duzce, and Ganos area with values up to $0.8-1.0 \mathrm{~g}$ in PGA with 10\% probability of exceedance in $50 \mathrm{yrs}$. The corresponding maximum values reach $1.0-1.5 \mathrm{~g}$ in the case of the $2 \%$ probability of exceedance in 50 yrs (Figure 17).

A comparison of the PSHA results based on the two earthquake occurrence probability models (Poisson and BPT) demonstrates the effect of the relative variations between the fault recurrence time and the elapsed time of fault rupture. In general, time-dependent hazard estimates enhance the ground motion probabilities for the faults other than those related with recent earthquakes (e.g., the Izmit 1999, Manyas 1964, Yenice 1953). The PGA values are higher in Izmit and Duzce, i.e., faults placed in the eastern part of the Marmara region, (around 0.8-1.0 g) for the Poisson model than for the BPT model, ( 0.4 and $0.6 \mathrm{~g}$ ) because the Poisson model is insensitive to the time passed since the last earthquake occurred in the fault. This effect appears in cases where the elapsed time from the last characteristic earthquake for a dominant fault is short with respect to its recurrence time, for example, the Izmit and Duzce faults ruptured in 1999, the elapsed time of 16 years actually being short with respect to their recurrence time of 160 and 155 years, respectively (Tables 3 and 4; Figures 17 and 20). Similarly, the elapsed times for the Manyas and Yenice faults, 51 and 62 years since the last earthquakes in 1964 and 1953 respectively, are significantly shorter when compared to their recurrence times of 567 and 1150 years.

Besides, some of the active fault segments retracing high renewal-BPT probabilities favor higher seismic hazard for the the Central Basin, MMF, Ganos, Saros, and Saros 2 segments in the central and eastern part of the Marmara Sea region. PGA is around 0.6-0.8 $\mathrm{g}$ for the time-independent model, while it increases almost 50-60\%, reaching 1.0-1.5 $\mathrm{g}$ in the same area close to these fault systems for the time-dependent case, thus making them one of the highest hazard zones in the Marmara region, close to the city of Istanbul. For example, the Central Basin and MMF segments have several times larger elapsed times (672 and 249 years) with respect to their calculated inter-event times, 130 and 115 years, respectively. These differences are further discussed in Section 6.3 where we also present the percentage changes in seismic hazard caused by the use of different models.

\subsection{Hazard Curves for Selected Sites}

Figures 23-25 present the PGA and 5\% damped Spectral Acceleration at $\mathrm{T}=0.2 \mathrm{~s}$ and $\mathrm{T}=1.0 \mathrm{~s}$ hazard curves for four major cities in the Marmara region, namely Istanbul, Tekirdağ, Bursa and Izmit. These cities are selected to reflect the short and long-term effects of the source models developed in this study. Istanbul and Tekirdağ are located close to the unruptured segments of the Main Marmara 
Fault, the hazard in Tekirdağ being the highest among all. Bursa is located directly on a fault segment (Bursa segment), however with a much longer mean recurrence time of the characteristic earthquake, and Izmit is again located directly on a fault segment (Izmit segment) which experienced a very recent rupture. Overall, the seismic hazard in Tekirdağ reveals to be the highest both in Poisson and time-dependent models. In Istanbul, although we observe quite high rates associated with low and mid-range ground motion values, we observe a steep decrease towards higher ground motion levels, i.e., the probabilities associated with PGA's larger than $1 \mathrm{~g}$, the rates of occurrences are lower than the other cities. This might be the effect of the larger distance between the city centre and the causative faults. In Bursa, due to the high return periods of large earthquakes we observe higher annual rates for larger ground motion amplitudes.

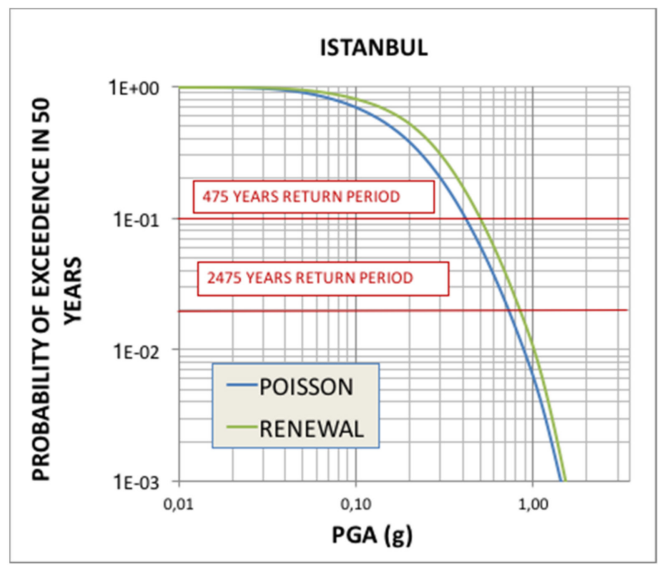

(a)

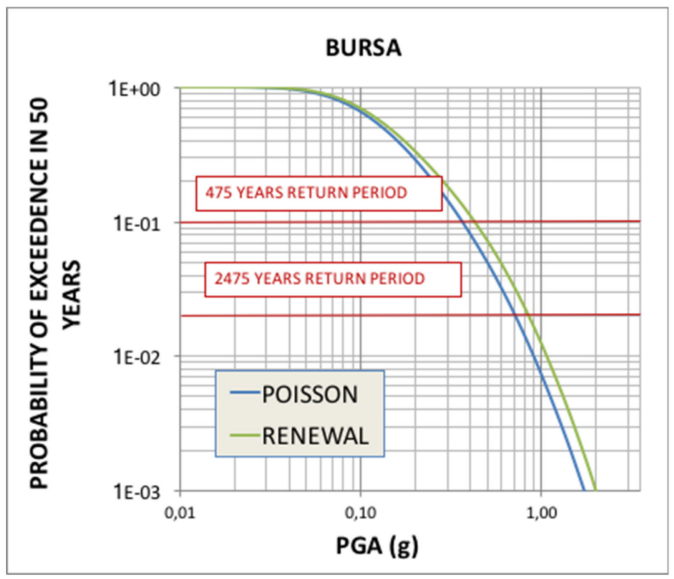

(c)

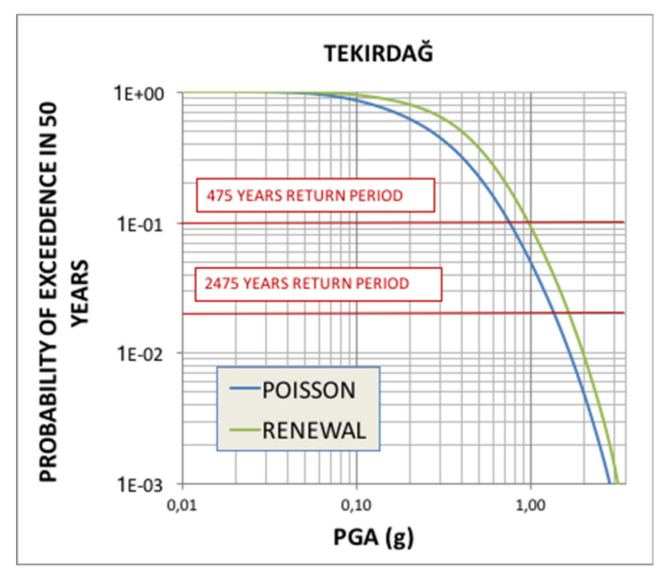

(b)

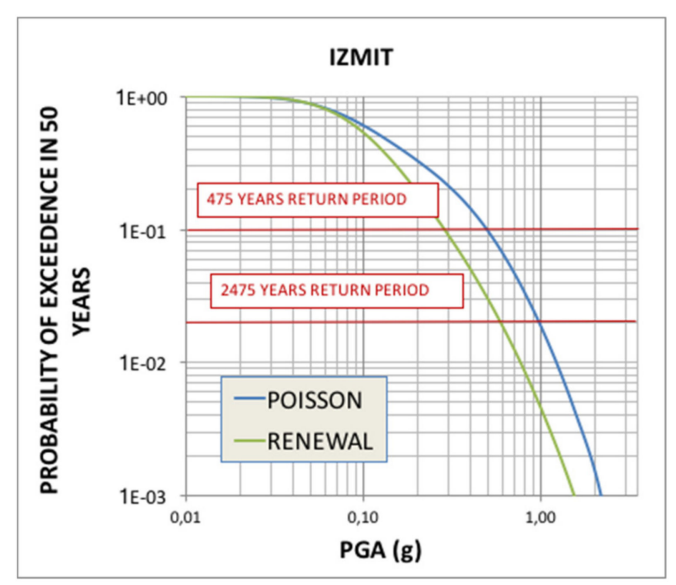

(d)

Figure 23. PGA hazard curves for (a) Istanbul, (b) Tekirdağ, (c) Bursa, and (d) Izmit (Kocaeli) obtained from Poisson and renewal models, both combined with smoothed seismicity at the background. 


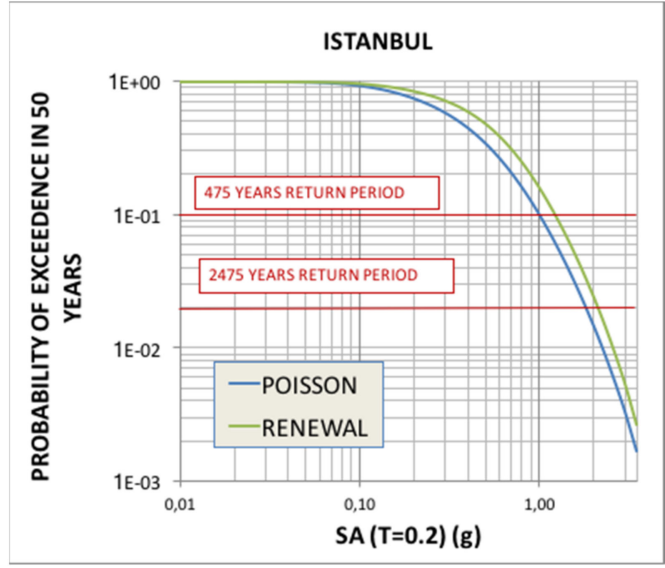

(a)

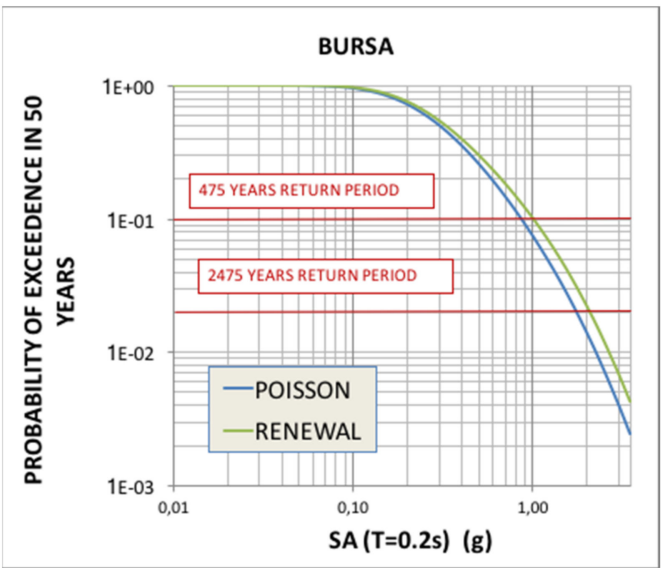

(c)

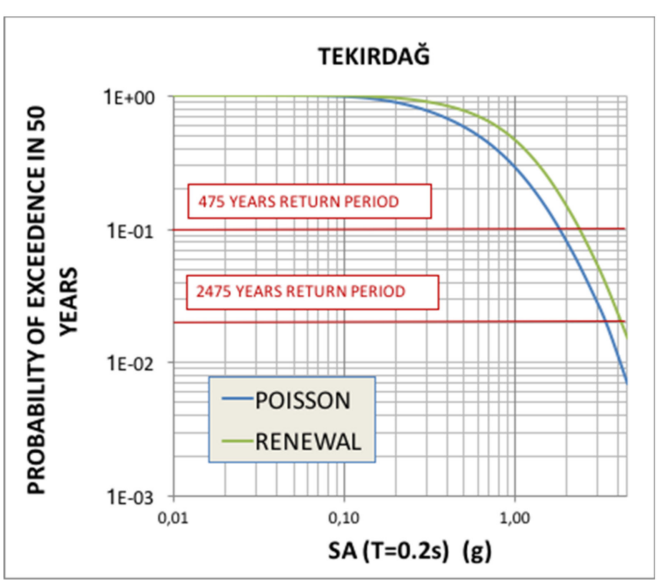

(b)

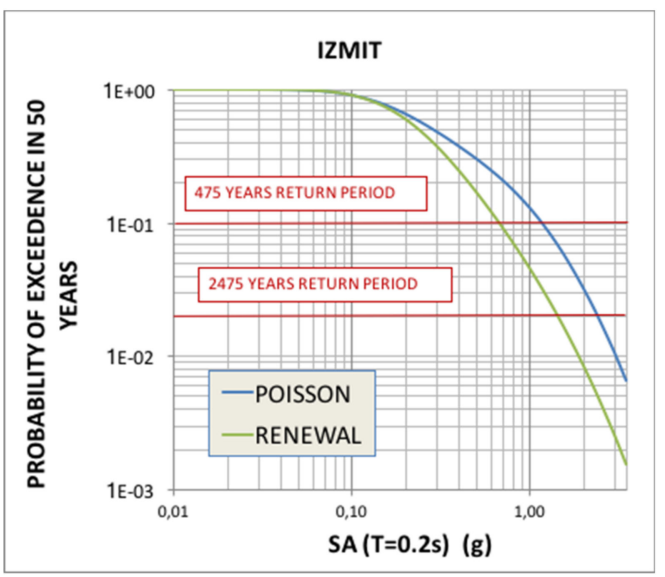

(d)

Figure 24. Five percent damped spectral acceleration (SA) at $\mathrm{T}=0.2 \mathrm{~s}$ hazard curves for (a) Istanbul, (b) Tekirdağ, (c) Bursa, and (d) Izmit (Kocaeli) obtained from Poisson and renewal models, both combined with smoothed seismicity at the background.

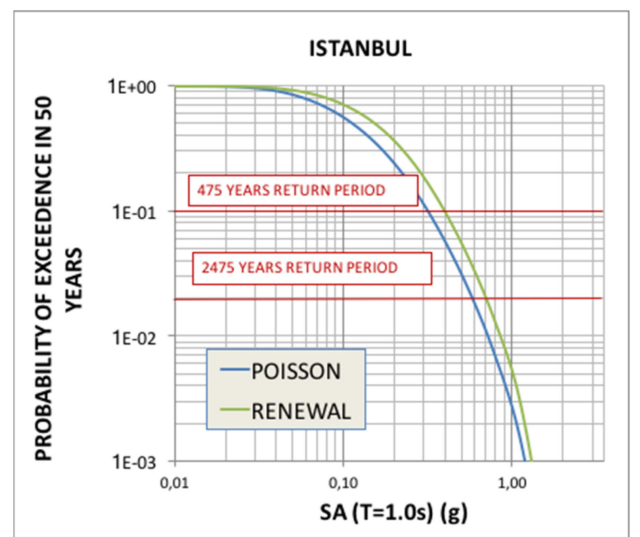

(a)

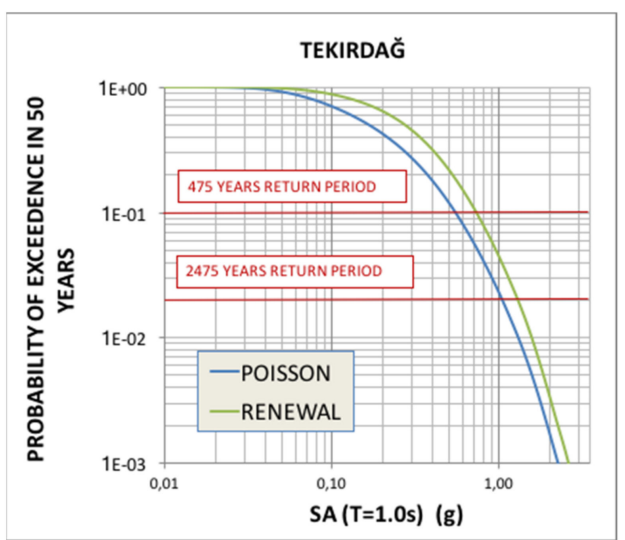

(b)

Figure 25. Cont. 


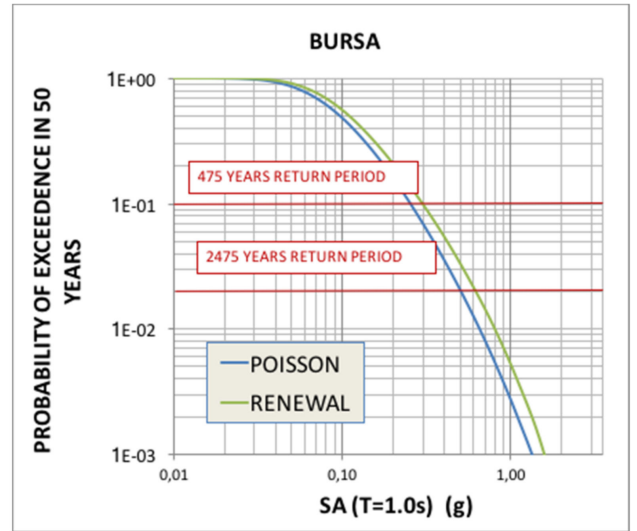

(c)

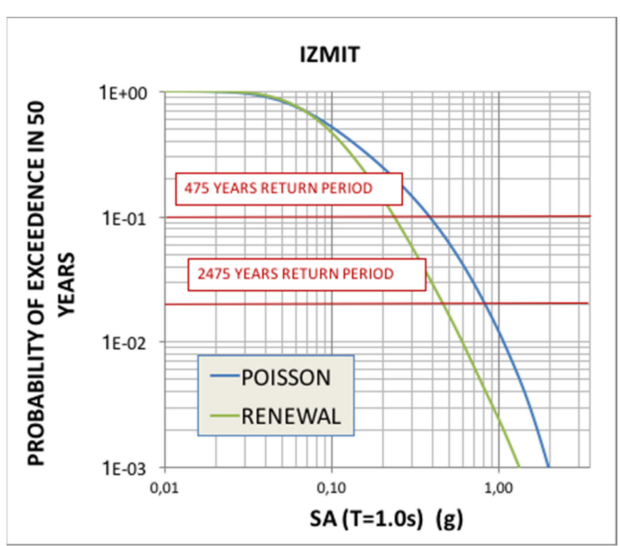

(d)

Figure 25. Five percent damped spectral acceleration (SA) at $\mathrm{T}=1.0 \mathrm{~s}$ hazard curves for (a) Istanbul, (b) Tekirdağ, (c) Bursa, and (d) Izmit (Kocaeli) obtained from Poisson and renewal models, both combined with smoothed seismicity at the background.

\subsection{Discussion of the Results and Comparisons with Other Studies}

In this section, we discuss the percentage changes between the seismic hazard maps, presented in terms of PGA with $10 \%$ probability exceedance in 50 years, from this and other studies, reflecting the effects of modelling preferences in the calculation of the total hazard (Equation 8) and the use of different databases, earthquake occurrence models, and GMPEs. In all the comparison maps, the relative differences, i.e., the percent changes, are expressed as:

$$
\left\{\left[\text { PSHA }_{\text {Model } 2}-\text { PSHA }_{\text {Model } 1}\right] / \text { PSHA }_{\text {Model } 1}\right\} \times 100
$$

Figure 26 shows the percent changes in the mean seismic hazard in terms of 475-year PGA computed with two earthquake occurrence models in the present study. The results based on the time-independent and time-dependent models present the impact of the fault recurrence rate and the regency of fault rupture by remarkably reducing hazard levels along the eastern part of the NAF zone reaching up to $60 \%$ nearby Izmit, Duzce, and an increase of up to $50 \%$ in the regions close to Istanbul and Tekirdağ. At Southern NAF Strands: Pazarkoy, Can and Manyas faults, we observe a 25\% decrease in the seismic hazard. The hazard curves presented in Figures 23-25 reveal similar trends for the 2475-year ground motions as well.

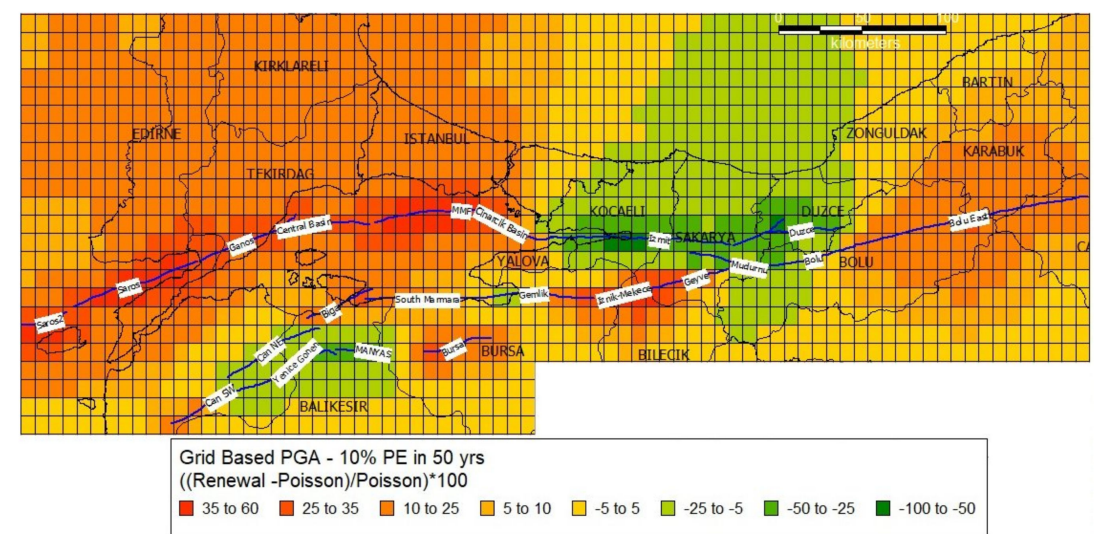

Figure 26. Difference map corresponding to renewal vs Poisson approaches for 475-year PGA. It represents the ratio between the mean PGA seismic hazard by $\left\{\left[P S H A_{\text {Renewal }}-\right.\right.$ PSHA $\left.\left.A_{\text {Poisson }}\right] / P S H A_{\text {Renewal }}\right\} \times 100$, Poisson and Renewal (\%10 in $50 \mathrm{yrs}$.), calculated using the background seismicity and individual fault segments. In red: positive amplifications. In green: negative amplifications. 
In Figure 27a,b we compare our Poisson and time-dependent seismic hazard results in terms of 475-year PGA with those previously calculated by Erdik et al. (2004). Our hazard model yields higher ground motion in the Marmara Sea both for Poisson and time-dependent models, and lower ground motion values around the Izmit segment. The main reason for these differences is in fact the development of a different fault segmentation model in the present study. For the Izmit segment, the reason for the Poisson PGA values being lower is that the new model incorporates the 1999 Izmit earthquake rupture as a single segment with a characteristic magnitude of 7.5 and return period of 155 years, while in the previous model it was composed of four different segments each having a characteristic magnitude of 7.2, return period of 140 years, and the accumulation of several M7.2 earthquakes causing higher annual rates of exceedances for the specific ground motion amplitudes. On the other hand, mean recurrence times associated with the characteristic ruptures on MMF and Central Basin are now much lower. Cinarcik segment is now associated with a dipping geometry $\left(70^{\circ}\right.$ dip), yielding higher ground motions over the entire surface projection of the segment. As no major earthquake occurred in the region since the publication of the previous model, time-dependent hazard is expected to increase in all parts of the region, however, this could be quantified only if the Poissonian differences were set to zero, i.e., by an update of the previous model to incorporate the increase in the parameter "time since last earthquake". However, these results are a clear example that indicate that hazard estimations may change over the time, increasing and decreasing as a function of time and with the knowledge that is introduced to the hazard calculations.

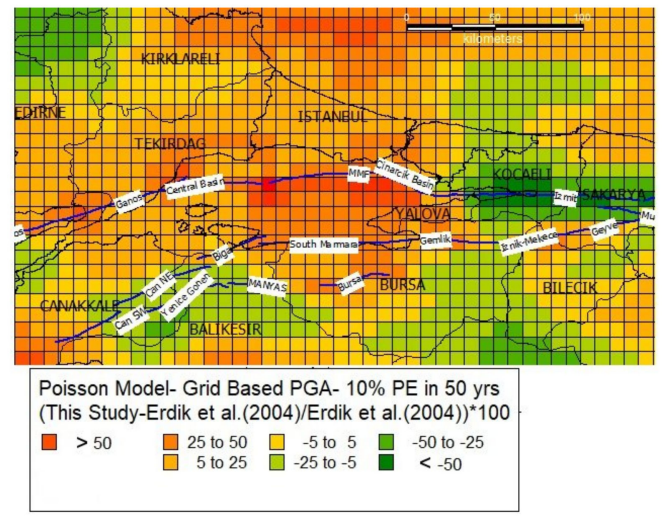

(a)

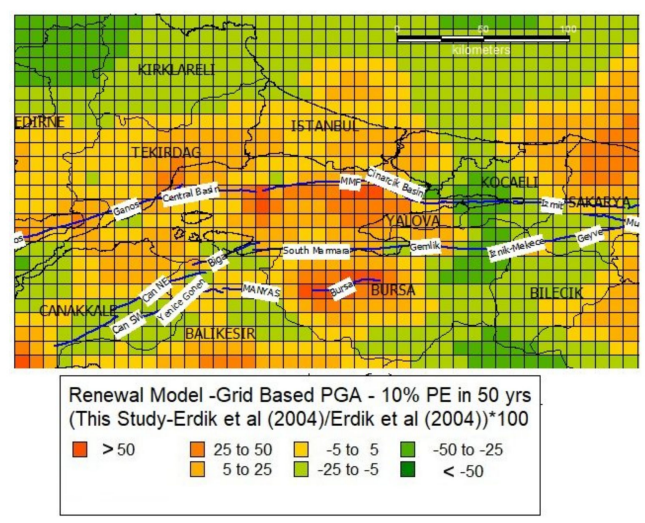

(b)

Figure 27. Difference map of the time-independent and time-dependent model results from this study and [9]. It represents the ratio between the mean PGA at $\left\{\left[P S H A_{\text {this study }}-P S H A_{\text {Erdik et al. }}[9]\right] / P S H A_{\text {this }}\right.$ study $\} \times 100$, Erdik et al. [9] and this study (\%10 in 50 yrs.). (a) Poisson model (b) renewal model, calculated using the background seismicity and individual fault segments. In red: positive amplifications. In green: negative amplifications.

Figure 28 presents a comparison of the 475-year PGA distribution of our Poisson model with the mean 475-year PGA from the updated PSHA model of Turkey [71-73]. It would be difficult to provide a full description of the source modelling in the latter; however, we may say that the new Turkish seismic hazard model is composed of two independent source models, an area source model (assigned 50\% weight in the final logic tree) and fault source and smoothed seismicity model (again weighted as $50 \%$ in the final logic tree). The earthquake recurrence is assumed to be Poisssonian with exponential distribution in all models. The seismic hazard as computed by our model is generally higher around the fault segments and lower in the background. Our characteristic Poisson ruptures yield much higher hazard values around the fault segments, as in the combined Turkey model, the area source model smooths the hazard in these regions. In the background, however, the same governs the hazard, yielding higher values than the smoothed seismicity model of the present study. It should also be stated that the GMPE logic tree is the same in both models. Although based on different modelling assumptions (characteristic modelling of earthquake recurrence on faults in the present 
case, exponential modelling of earthquake recurrence in the Turkey model, in addition to an area source model as another branch of the logic tree), we wanted to present a comparison of the resulting hazard maps, as it may provide guidance on the identification of regions, where site-specific hazard assessments with alternative models would yield more critical values when compared to the standard code-basis ground motions. The use of time-dependent recurrence models may further enhance these differences in regions close to un-ruptured faults.

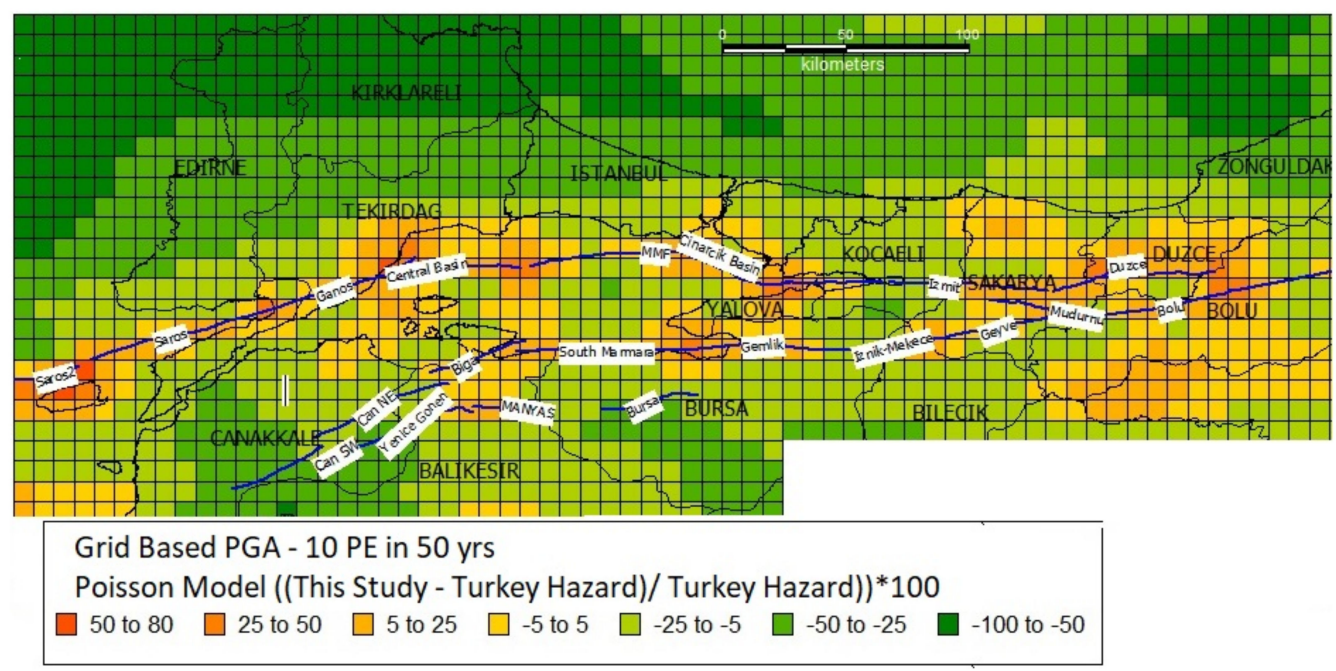

Figure 28. Difference map of the Poisson model results from this study and the new Turkish seismic hazard model. It represents the ratio between the mean PGA seismic hazard at $\left\{\left[P S H A_{\text {thisstudy }}-\right.\right.$ $\left.\left.P S H A_{\text {TurkeyHazard }}\right] / P S H A_{\text {TurkeyHazard }}\right\} \times 100$, Turkey Hazard and this study (\%10 in 50 yrs.) calculated using the background seismicity and individual fault segments. In red: positive amplifications. In green: negative amplifications.

\section{Conclusions}

In the present study, we produce both time-dependent and time-independent ground motion exceedance probabilities as well as ground motion distribution maps for the Marmara region. The selected ground motion parameters were PGA and 5\% damped Spectral Accelerations at structural periods of 0.2 and 1.0s. The first parameter is important as it provides a quick perception of the hazard levels at regional scale and is a convenient parameter for comparison with other studies, while the last two parameters can be readily used to construct NEHRP type design spectra for any site. Ground motion maps are presented for return periods of 475 and 2475 years corresponding to $10 \%$ and $2 \%$ probabilities of exceedance in 50 years. Our models incorporate recent information on the seismicity and the individual fault sources in the study region. These new and updated data permitted us to develop a new fault segmentation model and to assess the earthquake probabilities of the larger events and their effects on both the time-independent and time-dependent probabilistic seismic hazard analyses. In this study, we analyzed the effects of different considerations of the earthquake rupture model to the seismic hazard for a given exceedance probability. Particularly, we investigate model assumptions that lead to the most compelling alterations in the estimated hazard in the Marmara region, i.e., the impact of the different earthquake occurrence models on the seismic hazard using a PSHA methodology. We examined the effect of the recurrence time and the elapsed time since on the last earthquake associated with fault segments on the expected ground motion values in the next 50 years.

According to our results, the time-dependent ground motion estimations differ by 50 to $80 \%$ from the time-independent ones close to fault sources. When the elapsed time since the last earthquake exceeds half of the recurrence time of the fault, the time-dependent models contribute to higher probabilities and increase the seismic hazard compared to the time-independent ones [18]. 
The time-independent hazard maps indicate that PGA, with $10 \%$ probability of exceedance in 50 years, varies between 0.3 and $0.4 \mathrm{~g}$ in the city of Istanbul and 0.4 and $0.6 \mathrm{~g}$ in Izmit and Duzce region. The time-dependent BPT model gives a somewhat lower hazard, notably in Izmit, Duzce, Yenice, and Manyas areas, where recent fault ruptures are observed and amplified hazard in Central and Western Marmara region as well as in Bursa, where seismic gaps exist. Although significant differences are observed in absolute values, these results are in general in agreement with previous findings by [9].

The updated seismic hazard maps of Turkey, developed in connection with the new seismic design code, offer another source of comparison for the results of different modelling approaches. In the mentioned study, the design basis ground motions are obtained via a 50/50 combination of an area source model [72] and a fault source and smoothed seismicity model [73]. As the area source modelling tends to spread the hazard over the entire source area, our results remain higher around the main traces of the faults segments and generally lower over the background zones.

The present study aims to provide an update of the related previous work for the Marmara region in terms of PSHA results and particularly to demonstrate the effects of time-dependent seismic hazard modelling in a region where data availability enhances the construction of such models. Here we adopt a mean source model, with mean parameters computed from preferred models. Epistemic uncertainties associated with source characterization (e.g., uncertainties associated with geometric and kinematic parameters of the fault segments), multi-segment rupture probabilities and uncertainties caused by GMPE selection remain to be explored and quantified. The present study may help to pinpoint some of the key issues that affect earthquake occurrence and resulting ground motion hazard estimations, and particularly to note the importance of considering different and innovative approaches on the topics such as the earthquake recurrence, probability occurrence modelling, and ground motion modelling, for regional as well as for more detailed site-specific studies. For example, time-dependent hazard models may help to better categorize those areas with high seismic hazard for future earthquake microzonation studies and for the development of seismic risk-mitigation strategies, which might be relevant for urban planning and guidance in reconstruction and seismic retrofit.

Author Contributions: Investigation, K.Ş. and M.B.D.T.; Methodology, K.Ş. and A.A.; Software, M.B.D.T.; Validation, M.B.D.T. and A.A.; Writing—original draft, K.Ş. and A.A.; Writing-review \& editing, K.Ş., M.B.D.T. and A.A.

Funding: This study is supported by the MARSite (Marmara Supersite) "New Directions in Seismic-Hazard Assessment through Focused Earth Observation in the Marmara Supersite," European Integrated Project, THEME-ENV.2012.6.4-2 (Long-term monitoring experiment in geologically active regions of Europe prone to natural hazards: The Supersite concept), Grant Agreement Number 308417. The article processing charge (APC) is funded by the Centro di Pericolosita' Sismica (CPS) at the Instituto Nazionale di Geofisica e Vulcanologia (INGV).

Conflicts of Interest: The authors declare no conflict of interest.

\section{References}

1. Parsons, T.; Toda, S.; Stein, R.S.; Barka, A.; Dietrich, J.H. Heightened odds of large earthquakes near Istanbul: An interaction-based probability calculation. Science 2000, 288, 661-665. [CrossRef]

2. Parsons, T. Recalculated probability of $\mathrm{M} \geq 7$ earthquakes beneath the Sea of Marmara, Turkey. J. Geophys. Res. 2004, 109, B05304. [CrossRef]

3. Murru, M.; Akinci, A.; Falcone, G.; Pucci, S.; Console, R.; Parsons, T. M $\geq 7$ earthquake rupture forecast and time-dependent probability for the Sea of Marmara region, Turkey. J. Geophys. Res. 2016, 121, 2679-2707. [CrossRef]

4. Hubert-Ferrari, A.; Barka, A.; Jaques, E.; Nalbant, S.S.; Meyer, B.; Armijo, R.; Tapponnier, P.; King, G.C.P. Seismic hazard in the Marmara Sea region following the 17 August 1999 Izmit earthquake. Nature 2000, 404, 269-273. [CrossRef]

5. Armijo, R.; Pondard, N.; Meyer, B.; Uçarkuş, G.; Mercier de Le'pinay, B.; Malavieille, J.; Dominguez, S.; Gustcher, M.; Schmidt, S.; Beck, C.; et al. Submarine fault scarps in the Sea of Marmara pull-apart (North Anatolian Fault): Implications for seismic hazard in Istanbul. Geochem. Geophys. Geosyst. 2005, 6, Q06009. [CrossRef] 
6. Pondard, N.; Armijo, R.; King, G.C.P.; Meyer, B.; Flerit, F. Fault interactins in the Sea of Marmara pull-apart (North Anatolian fault): Earthquake clustering and propagating earthquake sequences. Geophys. J. Int. 2007, 171, 1185-1197. [CrossRef]

7. Bohnhoff, M.; Bulut, F.; Dresen, G.; Malin, P.E.; Eken, Y.; Aktar, M. An earthquake gap south of Istanbul. Nat. Commun. 2013, 4, 1999. [CrossRef]

8. Atakan, K.; Ojeda, A.; Meghraoui, M.; Barka, A.; Erdik, M.; Bodare, A. Seismic Hazard in Istanbul following the 17 August 1999 Izmit and 12 November 1999 Düzce earthquakes. Bull. Seismol. Soc. Am. 2002, 92, 466-482. [CrossRef]

9. Erdik, M.; Demircioğlu, M.; Şeşetyan, K.; Durukal, E.; Siyahi, B. Earthquake hazard in Marmara region, Turkey. Soil Dyn. Earthq. Eng. 2004, 24, 605-631. [CrossRef]

10. Kalkan, E.; Gülkan, P.; Yılmaz, N.; Çelebi, M. Re-examination of probabilistic seismic hazard in the Marmara Sea region. Bull. Seismol. Soc. Am. 2009, 99, 2127-2146. [CrossRef]

11. Gulerce, Z.; Ocak, S. Probabilistic seismic hazard assessment of Eastern Marmara Region. Bull. Earthq. Eng. 2013, 11, 1259-1277. [CrossRef]

12. Sørensen, M.B.; Pulido, N.; Atakan, K. Sensitivity of ground motion simulations to earthquake source parameters: A case study for Istanbul, Turkey. Bull. Seismol. Soc. Am. 2007, 97, 881-900. [CrossRef]

13. Ansal, A.; Akinci, A.; Cultrera, G.; Erdik, M.; Pessina, V.; Tuzce, G.; Ameri, G. Loss estimation in Istanbul based on deterministic earthquake scenarios in the Marmara Sea region, Turkey. Soil Dyn. Earth. Eng. 2009, 29, 699-709. [CrossRef]

14. Mert, A.; Fahjan, Y.M.; Hutchings, L.J.; Pınar, A. Physically based probabilistic seismic hazard analysis using broadband ground motion simulation: A case study for the Prince Islands Fault, Marmara Sea. Earth Planets Space 2016, 68, 146. [CrossRef]

15. Akinci, A.; Aochi, H.; Herrero, A.; Pischiutta, M.; Karanikas, D. Physics-Based Broadband Ground-Motion Simulations for Probable Mw $\geq 7.0$ Earthquakes in the Marmara Sea Region (Turkey). Bull. Seismol. Soc. Am. 2017, 107, 1307-1323. [CrossRef]

16. Spagnuolo, E.; Akinci, A.; Herrero, A.; Pucci, S. Implementing the effect of the rupture directivity on PSHA for the city of Istanbul, Turkey. Bull. Seismol. Soc. Am. 2016, 106. [CrossRef]

17. Akinci, A.; Galadini, F.; Pantosti, D.; Petersen, M.; Malagnini, L.; Perkins, D. Effect of Time Dependence on Probabilistic Seismic-Hazard Maps and Deaggregation for the Central Apennines, Italy. Bull. Seism. Soc. Am. 2009, 99, 585-610. [CrossRef]

18. Akinci, A.; Vannoli, P.; Falcone, G.; Taroni, M.; Tiberti, M.M.; Murru, M.; Burrato, P.; Mariucci, M.T. When time and faults matter: Towards a time-dependent probabilistic SHA in Calabria, Italy. Bull. Earthq. Eng. 2017, 15, 2497-2524. [CrossRef]

19. Pagani, M.; Monelli, D.; Weatherill, G.; Danciu, L.; Crowley, H.; Silva, V.; Henshaw, P.; Butler, L.; Nastasi, M.; Panzeri, L.; et al. OpenQuake Engine: An open hazard (and risk) software for the Global Earthquake Model. Seismol. Res. Lett. 2014, 85, 692-702. [CrossRef]

20. Erdik, M.; Biro, Y.; Onur, T.; Sesetyan, K.; Birgoren, G. Assessment of earthquake hazard in Turkey and neighboring regions. Ann. Geofis. 1999, 42, 1125-1138.

21. Youngs, R.R.; Coppersmith, K.J. Implications of fault slip rates and earthquake recurrence models to probabilistic seismic hazard estimates. Bull. Seismol. Soc. Am. 1985, 75, 939-964. [CrossRef]

22. Ambraseys, N.N.; Simpson, K.A.; Bommer, J.J. Prediction of Horizontal Response Spectra in Europe. Earthq. Eng. Struct. Dyn. 1996, 25, 371-400. [CrossRef]

23. Boore, D.M.; Joyner, W.B.; Fumal, T.E. Equations for estimating horizontal response spectra and peak acceleration from Western North American earthquakes: A summary of recent work. Seismol. Res. Lett. 1997, 68, 128-153. [CrossRef]

24. Campbell, K.W. Empirical Near-Source Attenuation Relationships for Horizontal and Vertical Components of Peak Ground Acceleration, Peak Ground Velocity, and Pseudo-Absolute Acceleration Response Spectra. Seismol. Res. Lett. 1997, 68, 154-179. [CrossRef]

25. Sadigh, K.; Chang, C.Y.; Egan, J.A.; Makdisi, F.; Youngs, R.R. Attenuation Relationships for Shallow Crustal Earthquakes Based on California Strong Motion Data. Seismol. Res. Lett. 1997, 68, 180-189. [CrossRef]

26. Boore, D.M.; Atkinson, G.A. Ground motion prediction equations for the average horizontal component of PGA, PGV, PGD, and 5\% damped PSA art spectral periods between $0.01 \mathrm{~s}$ and $10.0 \mathrm{~s}$. Earthq. Spectra 2008, 24, 99-138. [CrossRef] 
27. Campbell, K.W.; Bozorgnia, Y. NGA ground motion model for the geometric mean horizontal component of PGA, PGV, PGD and 5\% damped linear elastic response spectra for periods ranging from 0.01 to 10 s. Earthq. Spectra 2008, 24, 139-171. [CrossRef]

28. Chiou, B.S.J.; Youngs, R.R. An NGA model for the average horizontal component of peak ground motion and response spectra. Earthq. Spectra 2008, 24, 173-215. [CrossRef]

29. Kalkan, E.; Gülkan, P. Site-dependent spectra derived from ground motion records in Turkey. Earthq. Spectra 2004, 20, 1111-1138. [CrossRef]

30. Abrahamson, N.A.; Silva, W.J. Summary of the Abrahamson \& Silva NGA ground-motion relations. Earthq. Spectra 2008, 24, 67-97.

31. Idriss, I.M. An NGA empirical model for estimating the horizontal spectral values generated by shallow crustal earthquakes. Earthq. Spectra 2008, 24, 217-242. [CrossRef]

32. Stucchi, M.; Rovida, A.; Gomez Capera, A.A.; Alexandre, P.; Camelbeeck, T.; Demircioglu, M.B.; Gasperini, P.; Kouskouna, V.; Musson, R.M.W.; Radulian, M.; et al. The SHARE European Earthquake Catalogue (SHEEC) 1000-1899. J. Seismol. 2012, 17, 523-544. [CrossRef]

33. Albini, P.; Musson, R.M.W.; Gomez Capera, A.A.; Locati, M.; Rovida, A.; Stucchi, M.; Viganò, D. Global Historical Earthquake Archive and Catalogue (1000-1903); GEM Foundation: Pavia, Italy, 2013.

34. Albini, P.; Musson, R.M.W.; Rovida, A.; Locati, M.; Gomez Capera, A.A.; Viganò, D. The Global Earthquake History. Earthq. Spectra 2014, 30, 607-624. [CrossRef]

35. Storchak, D.A.; Di Giacomo, D.; Bondar, I.; Engdahl, E.R.; Harris, J.; Lee, W.H.; Villaseñor, A.; Bormann, P. Public release of the ISC-GEM global instrumental earthquake catalogue (1900-2009). Seismol. Res. Lett. 2013, 84, 10-815. [CrossRef]

36. Kadirioğlu, F.T.; Kartal, R.F.; Kılıç, T.; Kalafat, D.; Duman, T.Y.; Azak, T.E.; Özalp, S.; Emre, Ö. An improved earthquake catalogue $(\mathrm{M} \geq 4.0)$ for Turkey and its near vicinity (1900-2012). Bull. Earthq. Eng. 2016, 16. [CrossRef]

37. Guidoboni, E.; Comastri, A. Catalogue of Earthquakes and Tsunamis in the Mediterranean Area from the 11th to the 15th Century; Istituto Nazionale di Geofisica e Vulcanologia: Rome, Italy, 2005.

38. Ambraseys, N. Earthquakes in the Mediterranean and Middle East: A Multidisciplinary Study of Seismicity up to 1900; Cambridge University Press: Cambridge, UK, 2009.

39. Gardner, J.K.; Knopoff, L. Is the sequence of earthquakes in Southern California, with aftershocks removed, Poissonian? Bull. Seismol. Soc. Am. 1974, 64, 1363-1367.

40. Barka, A.A. Slip distribution along the North Anatolian fault associated with the large earthquakes of the period 1939 to 1967. Bull. Seismol. Soc. Am. 1996, 86, 238-1254.

41. Wong, H.K.; Lüdmann, T.; Uluğ, A.; Görür, N. The Sea of Marmara: A plate boundary sea in an escape tectonic regime. Tectonophysics 1995, 244, 231-250. [CrossRef]

42. Armijo, R.; Meyer, B.; Hubert, A.; Barka, A. Westwards propagation of the North Anatolian fault into the northern Aegean: Timing and kinematics. Geology 1999, 27, 267-270. [CrossRef]

43. Armijo, R.; Meyer, B.; Navarro, S.; King, G.; Barka, A. Asymmetric slip partitioning in the Sea of Marmara pull-apart: A clue to propagation processes of the North Anatolian fault? Terra Nova 2002, 14, 80-86. [CrossRef]

44. Okay, A.; Demirbağ, E.; Kurt, H.; Okay, N.; Kuşcu, I. An active, deep marine strike-slip basin along the North Anatolian fault in Turkey. Tectonics 1999, 18, 129-147. [CrossRef]

45. Le Pichon, X.; Şengör, A.M.C.; Demirbă̆, E.; Rangin, C.; İmren, C.; Armijo, R.; Görür, N.; Çağatay, N.; Mercier de Lepinay, B.; Meyer, B.; et al. The active Main Marmara fault. Earth Planet. Sci. Lett. 2001, 192, 595-616. [CrossRef]

46. Yaltırak, C. Tectonic evaluation of Marmara Sea and its surroundings. Mar. Geol. 2002, 3175, 1-37. [CrossRef]

47. McNeill, L.C.; Mille, A.; Minshull, T.A.; Bull, J.M.; Kenyon, N.H.; Ivanov, M. Extension of the North Anatolian fault into the North Aegean trough: Evidence for transtension, strain partitioning, and analogues for Sea of Marmara basin models. Tectonics 2004, 23. [CrossRef]

48. Barka, A.; Kadinsky-Cade, K. Strike-slip fault geometry in Turkey and its influence on earthquake activity. Tectonics 1988, 7, 663-684. [CrossRef]

49. Emre, Ö.; Duman, T.Y.; Özalp, S.; Elmacı, H.; Olgun, Ş.; Şaroğlu, Ş. Active fault map of Turkey with explanatory text. Available online: http://www.mta.gov.tr/eng/maps/active-fault-1250000 (accessed on 14 November 2019). 
50. Hergert, T.; Heidbach, O. Slip-rate variability and distributed deformation in the Marmara Sea fault system. Nat. Geosci. 2010, 3, 132-135. [CrossRef]

51. Aksu, A.E.; Calon, T.J.; Hiscott, R.N.; Yasar, D. Anatomy of the North Anatolian fault zone in the Marmara Sea, western Turkey: Extensional basins above a continental transform. GSA Today 2000, 6, 3-7.

52. Imren, C.; Le Pichon, X.; Rangin, C.; Demirbag, E.; Ecevitoglu, B.; Görür, N. The North Anatolian fault within the Sea of Marmara: A new interpretation based on multi-channel seismic and multi-beam bathymetry data. Earth Planet. Sci. Lett. 2001, 186, 143-158. [CrossRef]

53. Ergintav, S.; Reilinger, R.E.; Çakmak, R.; Floyd, M.; Cakir, Z.; Doğan, U.; King, R.W.; McClusky, S.; Özener, H. Istanbul's earthquake hot spots: Geodetic constraints on strain accumulation along faults in the Marmara seismic gap. Geophys. Res. Lett. 2014, 41, 5783-5788. [CrossRef]

54. Meade, B.; Hager, B.; McClusky, S.; Reilinger, R.E.; Ergintav, S.; Lenk, O.; Barka, A.; Özener, H. Estimates of seismic potential in the Marmara Sea region from block models of secular deformation constrained by global positioning system measurements. Bull. Seismol. Soc. Am. 2002, 92, 208-215. [CrossRef]

55. Selim, H.H.; Tüysüz, O.; Karakas, A.; Tas, K.O. Morphotectonic evidence from $€$ the southern branch of the North Anatolian Fault (NAF) and basins of the south Marmara sub-region, NW Turkey. Quat. Int. 2013, 292, 176-192. [CrossRef]

56. Straub, C.; Kahle, H.G.; Schindler, C. GPS and geological estimates of the tectonic activity in the Marmara Sea region, NW Anatolia. J. Geophys. Res. 1997, 102, 27587-27601. [CrossRef]

57. Frankel, A. Mapping seismic hazard in the Central and Eastern United States. Seismol. Res. Lett. 1995, 66, 8-21. [CrossRef]

58. Akinci, A. HAZGRIDX: Earthquake Forecasting Model for ML $\geq 5.0$ Earthquakes in Italy Based on Spatially Smoothed Seismicity. Ann. Geophys. 2010, 53, 51-61. [CrossRef]

59. Schwartz, D.P.; Coppersmith, K.J. Fault behavior and characteristic earthquakes: Examples from the Wasatch and San Andreas fault zones. J. Geophys. Res. 1984, 89, 5681-5698. [CrossRef]

60. Field, E.H.; Jackson, D.D.; Dolan, J.F. A mutually consistent seismic-hazard source model for Southern California. Bull. Seismol. Soc. Am. 1999, 89, 559-578.

61. Gutenberg, B.; Richter, C.F. Frequency of earthquakes in California. Bull. Seismol. Soc. Am. 1949, 34, $185-188$.

62. Weichert, D.H. Estimation of the earthquake recurrence parameters for unequal observation periods for different magnitudes. Bull. Seismol. Soc. Am. 1980, 70, 1337-1346.

63. Wells, D.L.; Coppersmith, K.J. Empirical relationships among magnitude, rupture length, rupture width, rupture area, and surface displacement. Bull. Seismol. Soc. Am. 1994, 84, 974-1002.

64. Hanks, T.C.; Kanamori, H.A. Moment Magnitude Scale. J. Geophys. Res. 1979, 84, 2348-2350. [CrossRef]

65. Matthews, M.V.; Ellsworth, W.L.; Reasenberg, P.A. A Brownian model for recurrent earthquakes. Bull. Seismol. Soc. Am. 2002, 92, 2233-2250. [CrossRef]

66. Ellsworth, W.L.; Matthews, M.V.; Nadeau, R.M.; Nishenko, S.P.; Reasenberg, P.A.; Simpson, R.W. A physically based earthquake recurrence model for estimation of long-term earthquake probabilities. US Geol. Surv. Open File Rep. 1999, 522, 23.

67. Wu, S.C.; Cornell, C.A.; Winterstein, S.R. A hybrid recurrence model and its implication on seismic hazard results. Bull. Seismol. Soc. Am. 1995, 85, 1-16.

68. Working Group Calif. Earthquake Probabilities (WGCEP) Seismic hazards in southern California: Probable earthquakes, 1994-2014. Bull. Seismol. Soc. Am. 1995, 85, 379-439.

69. Reiter, L. Earthquake Hazard Analysis: Issues and Insights; Columbia University Press: New York, NY, USA, 1990.

70. Akkar, S.; Kale, Ö.; Yakut, A.; Çeken, U. Ground-motion characterization for the probabilistic seismic hazard assessment in Turkey. Bull. Earthq. Eng. 2018, 16, 3439-3463. [CrossRef]

71. Akkar, S.; Eroğlu Azak, T.; Çan, T.; Çeken, U.; Demircioğlu Tümsa, M.B.; Duman, T.Y.; Erdik, Ö.M.; Ergintav, S.; Kadirioğlu, F.T.; Kalafat, D.; et al. Evolution of seismic hazard maps in Turkey. Bull. Earthq. Eng. 2018, 16, 3197-3228. [CrossRef]

72. Şeşetyan, K.; Demircioğlu, M.B.; Duman, T.; Çan, T.; Tekin, S.; Eroğlu, T.; Zulfikar Fercan, Ö. A probabilistic seismic hazard assessment for the Turkish territory—Part I: The area source model. Bull. Earthq. Eng. 2018, 16, 3367-3397. [CrossRef]

73. Demircioglu, M.B.; Sesetyan, K.; Duman, T.Y.; Çan, T.; Tekin, S.; Ergintav, S. A probabilistic seismic hazard assessment for the Turkish territory: Part II-Fault source and background seismicity model. Bull. Earthq. Eng. 2018, 16, 3399-3438. [CrossRef] 
74. Akkar, S.; Cağnan, Z. A Local Ground-Motion Predictive Model for Turkey, and Its Comparison with Other Regional and Global Ground-Motion Models. Bull. Seismol. Soc. Am. 2010, 100, 2978-2995. [CrossRef]

75. Akkar, S.; Sandıkkaya, M.A.; Bommer, J.J. Empirical ground-motion models for point-and extended-source crustal earthquake scenarios in Europe and the Middle East. Bull. Earthq. Eng. 2014, 12, 359-387. [CrossRef]

76. Zhao, J.X.; Zhang, J.; Asano, A.; Ohno, Y.; Oouchi, T.; Takahashi, T.; Ogawa, H.; Irikura, K.; Thio, H.K.; Somerville, P.G.; et al. Attenuation relations of strong ground motion in Japan using site classification based on predominant period. Bull. Seismol. Soc. Am. 2006, 96, 898-913. [CrossRef]

(C) 2019 by the authors. Licensee MDPI, Basel, Switzerland. This article is an open access article distributed under the terms and conditions of the Creative Commons Attribution (CC BY) license (http://creativecommons.org/licenses/by/4.0/). 